\title{
Cascades of Homeostatic Dysregulation Promote Incubation of Cocaine Craving
}

\author{
일 Junshi Wang, ${ }^{1}$ Masago Ishikawa, ${ }^{1}$ Yue Yang, ${ }^{1}$ Mami Otaka, ${ }^{1}$ James Y. Kim, ${ }^{1}$ George R. Gardner, ${ }^{1}$ Michael T. Stefanik,

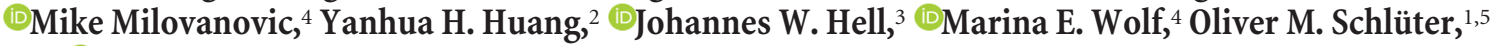 \\ and $\odot$ Yan Dong ${ }^{1,2}$ \\ Departments of ${ }^{1}$ Neuroscience, ${ }^{2}$ Psychiatry, University of Pittsburgh, Pittsburgh, Pennsylvania 15260, ${ }^{3}$ Department of Pharmacology, University of California, \\ Davis, Davis, California 95615, ${ }^{4}$ Department of Neuroscience, Rosalind Franklin University of Medicine and Science, North Chicago, Illinois 60064, and ${ }^{5}$ Department \\ of Psychiatry and Psychotherapy, University Medical Center, 37075 Göttingen, Germany
}

In human drug users, cue-induced drug craving progressively intensifies after drug abstinence, promoting drug relapse. This timedependent progression of drug craving is recapitulated in rodent models, in which rats exhibit progressive intensification of cue-induced drug seeking after withdrawal from drug self-administration, a phenomenon termed incubation of drug craving. Although recent results suggest that functional alterations of the nucleus accumbens (NAc) contribute to incubation of drug craving, it remains poorly understood how NAc function evolves after drug withdrawal to progressively intensify drug seeking. The functional output of NAc relies on how the membrane excitability of its principal medium spiny neurons (MSNs) translates excitatory synaptic inputs into action potential firing. Here, we report a synapse-membrane homeostatic crosstalk (SMHC) in male rats, through which an increase or decrease in the excitatory synaptic strength induces a homeostatic decrease or increase in the intrinsic membrane excitability of NAc MSNs, and vice versa. After short-term withdrawal from cocaine self-administration, despite no actual change in the AMPA receptor-mediated excitatory synaptic strength, GluN2B NMDA receptors, the SMHC sensors of synaptic strength, are upregulated. This may create false SMHC signals, leading to a decrease in the membrane excitability of NAc MSNs. The decreased membrane excitability subsequently induces another round of SMHC, leading to synaptic accumulation of calcium-permeable AMPA receptors and upregulation of excitatory synaptic strength after long-term withdrawal from cocaine. Disrupting SMHC-based dysregulation cascades after cocaine exposure prevents incubation of cocaine craving. Thus, cocaine triggers cascades of SMHC-based dysregulation in NAc MSNs, promoting incubated cocaine seeking after drug withdrawal.

Key words: cocaine; excitatory synapse; homeostatic plasticity; incubation; membrane excitability; nucleus accumbens

Significance Statement

Here, we report a bidirectional homeostatic plasticity between the excitatory synaptic input and membrane excitability of nucleus accumbens (NAc) medium spiny neurons (MSNs), through which an increase or decrease in the excitatory synaptic strength induces a homeostatic decrease or increase in the membrane excitability, and vice versa. Cocaine self-administration creates a false homeostatic signal that engages this synapse-membrane homeostatic crosstalk mechanism, and produces cascades of alterations in excitatory synapses and membrane properties of NAc MSNs after withdrawal from cocaine. Experimentally preventing this homeostatic dysregulation cascade prevents the progressive intensification of cocaine seeking after drug withdrawal. These results provide a novel mechanism through which drug-induced homeostatic dysregulation cascades progressively alter the functional output of NAc MSNs and promote drug relapse.

\section{Introduction}

Drug addiction is a pathological emotional and motivational state resulting from neural alterations after exposure to drugs of abuse (Nestler, 2001). Whereas many drug-induced cellular al-

Received Nov. 20, 2017; revised Jan. 18, 2018; accepted Jan. 22, 2018

Author contributions: J.W., M.I., Y.Y., M.O., M.T.S., Y.H.H., J.W.H., M.E.W., O.M.S., and Y.D. designed research;

J.W., M.I., Y.Y., M.O., J.Y.K., G.R.G., M.T.S., and M.M. performed research; J.W., M.I., M.T.S., and M.M. analyzed data;

J.W., Y.H.H., J.W.H., M.E.W., O.M.S., and Y.D. wrote the paper. terations have a signature of Hebbian plasticity (White, 1996; Hyman et al., 2006), others are thought to be homeostatic responses, i.e., they are induced to compensate for altered functional output of neurons or neural circuits (Aghajanian, 1978; 
Nestler and Aghajanian, 1997; Kalivas, 2005; Huang et al., 2011; Dong et al., 2017). Homeostatic responses are important in maintaining a stable function of the brain, but they can also go awry (Huang et al., 2011; Dong et al., 2017). Indeed, homeostatic dysregulation has long been hypothesized as a key mechanism underlying the progression of the addictive state (Koob and Le Moal, 1997). However, how addiction-related homeostatic alterations are formed and evolve remains poorly understood.

Human drug users can experience progressive intensification of cue-induced drug craving, a risk factor for relapse, after drug abstinence (Parvaz et al., 2016; Wolf, 2016). This time-dependent change is recapitulated in rodent models, in which rats exhibit progressive intensification of cue-induced cocaine seeking after withdrawal from cocaine self-administration, a phenomenon termed incubation of cocaine craving (Grimm et al., 2001). A prominent feature of incubation is that it occurs when drug withdrawal takes place in the home cage, with no apparent Hebbian stimulation present. This prompted us to explore the role of homeostatic plasticity in incubation of cocaine craving.

Although incubation of cocaine craving involves many cellular mechanisms, increasing evidence suggests that functional changes in medium spiny neurons (MSNs) in the nucleus accumbens (NAc) play a critical role (Wolf, 2016). The functional output of NAc MSNs relies on the integration of excitatory synaptic activity and membrane excitability. By definition, the functional output of a neuron is action potential firing. Lacking endogenous pace-making mechanisms, NAc MSNs rely on excitatory synaptic drive to climb toward the threshold of action potentials and, around the threshold, the membrane excitability determines how many action potentials will fire (O'Donnell et al., 1999). The excitatory postsynaptic strength is primarily determined by AMPA receptors (AMPARs), and the membrane excitability is determined by a variety of ion channels.

Incubation of cocaine craving begins in the first week of withdrawal and plateaus after a month or so (Lu et al., 2004). After short-term (e.g., 1-2 d) withdrawal from cocaine selfadministration, whereas the AMPAR-mediated excitatory synaptic strength of NAc MSNs remains largely unchanged, the membrane excitability is decreased (Conrad et al., 2008; Mu et al., 2010; Wolf, 2016). After long-term (e.g., 45 d) withdrawal, the excitatory synaptic strength of NAc MSNs is increased through synaptic accumulation of calcium-permeable (CP) AMPARs (Conrad et al., 2008; Wolf, 2016). Thus, membrane excitability and excitatory synaptic strength of NAc MSNs are altered sequentially after withdrawal from cocaine. In the present study, focused on NAc shell (NAcSh) MSNs, we demonstrate that these sequential changes are mechanistically linked through homeostatic dysregulation cascades.

Specifically, our results show that the excitatory synaptic activity and membrane excitability of NAcSh MSNs are coordinated via a synapse-membrane homeostatic crosstalk (SMHC), through which an increase or decrease in excitatory synaptic strength induces a homeostatic decrease or increase in the membrane excitability. Furthermore, we show that GluN2Bcontaining NMDARs function as synaptic sensors, which detect alterations in synaptic AMPARs. During cocaine self-

Dr. A. Barria for providing GluN2B constructs, Kevin Tang for excellent technical support, and Robert Malenka for helpful suggestions on the paper.

The authors declare no competing financial interests.

Correspondence should be addressed to Dr. Yan Dong, Department of Neuroscience, University of Pittsburgh, A210 Langley Hall, 5th and Ruskin Avenue, Pittsburgh, PA 15260. E-mail: yandong@pitt.edu.

DOI:10.1523/JNEUROSCI.3291-17.2018

Copyright $\odot 2018$ the authors $\quad 0270-6474 / 18 / 384317-13 \$ 15.00 / 0$ administration and early withdrawal, although the AMPARmediated synaptic strength in NAcSh MSNs is not altered, synaptic GluN2B NMDAR-signaling is upregulated. This triggers the first round of SMHC to decrease the membrane excitability of NAcSh MSNs. Subsequently, the decreased membrane excitability initiates the second round of SMHC, resulting in synaptic accumulation of CP AMPARs and strengthening of NAc excitatory synapses after long-term withdrawal from cocaine. Preventing the progression of these homeostatic dysregulation cascades in NAcSh MSNs after withdrawal from cocaine prevents incubation of cocaine craving. These results delineate a cellular mechanism through which cocaine-induced homeostatic dysregulation promotes drug relapse after withdrawal.

\section{Materials and Methods}

Subjects. Male Sprague-Dawley rats (Simonsen Laboratories; Harlan Laboratories) 35- to 45-d old upon arrival were used in most experiments. They were given $\sim 1$ week for acclimation to the housing environment before experimental procedures. Some rats were used at postnatal day 6 for slice cultures (Fig. 1). Male C57BL/6J GluN2B knock-in mice (Halt et al., 2012) of 4-8 weeks old were used in experiments presented in Figure $2 \mathrm{~J}, \mathrm{~K}$. Rats and mice were housed on a regular $12 \mathrm{~h}$ light/dark cycle (light on at 07:00 A.M.) with food and water ad libitum.

Repeated intraperitoneal injection of cocaine. We used a $5 \mathrm{~d}$ cocaine procedure, similar to earlier studies (Dong et al., 2005, 2006). Briefly, once per day for $5 \mathrm{~d}$, rats were taken out of the home cage for an intraperitoneal injection of either cocaine $\mathrm{HCl}(15 \mathrm{mg} / \mathrm{kg}$ in saline) or the same volume of saline (control), and placed back in the home cages immediately.

Virus preparation and in vivo delivery. The wild-type (wt) and mutant (m) GluN2B (RS/QD) constructs were described previously (Barria and Malinow, 2005). The cDNA for wtGluN2B-GFP or mGluN2B-GFP was cloned into the recombinant, replication-defective Sindbis virus backbone vector (pSINrep2S ${ }^{726}$ ). The protocol for making Sindbis virus was similar to that used previously (Marie et al., 2005; Dong et al., 2006; Huang et al., 2008), except that the toxicity was further minimized by using a new Sindbis virus-based vector, pSINrep (nsP2S $\left.{ }^{726}\right)$. The GluN2B-, SK2, and luciferase control-RNAi (bu2Bd: GCTGGTGATAATCCTTCTGAA; suSKc: GCCAGAGTCATGCTATTACAT; shLC: CCTAAGGTTAAGTCGCCCTCG) were packaged into a recombinant AAV2 vector pseudotyped with AAV8 capsids (referred to as AAV2/8 in the text) as previously described (Huang et al., 2015).

To infect in vivo NAcSh MSNs, a stereotaxic microinjection technique was used. Briefly, rats were anesthetized with $1-3 \%$ isoflurane gas and a stainless steel cannula (31 gauge) was implanted bilaterally into the NAcSh (in mm: A: $+1.65 ; \mathrm{L}: \pm 0.8 ; \mathrm{D}:-7.65$ ). Concentrated viral solutions $(1 \mu \mathrm{l} / \mathrm{side})$ were infused into the NAcSh through a pump at a flow rate of $0.2 \mu \mathrm{l} / \mathrm{min}$. The injection cannula was left in place for $5 \mathrm{~min}$ and then slowly withdrawn. After the skin was sutured, the rats were placed on the heating pad for postsurgical recovery. After waking up, rats were transferred to regular housing cages, where they were individually housed. For experiments involving Sindbis virus, the electrophysiological recordings of infected MSNs were performed 1-2 d following the viral injection. For experiments involving AAV2/8, recordings were performed $>3$ weeks after viral injection, and viral injection was often combined with the self-administration surgery using a multi-surgical procedure. Infected neurons were identified in living slices by their fluorescent signals using epifluorescence microscopy.

Intravenous surgery. Rats were anesthetized with a xylazine-ketamine mixture (5-10/50-100 mg/kg, i.p.). Ketoprofen ( $5 \mathrm{mg} / \mathrm{kg}$, s.c.) was given as an additional analgesic agent when need. The silicone catheter was inserted into the jugular vein passing subcutaneously to the midscapular region and connected to a vascular access button (Instech Laboratories) implanted under the skin. The rats were then single-housed for 5-7 d to recover before the training sessions. Catheters were flushed with sterile saline containing gentamycin $(5 \mathrm{mg} / \mathrm{ml})$ and heparin $(10 \mathrm{U} / \mathrm{ml})$ every $24 \mathrm{~h}$ during recovery and training. 

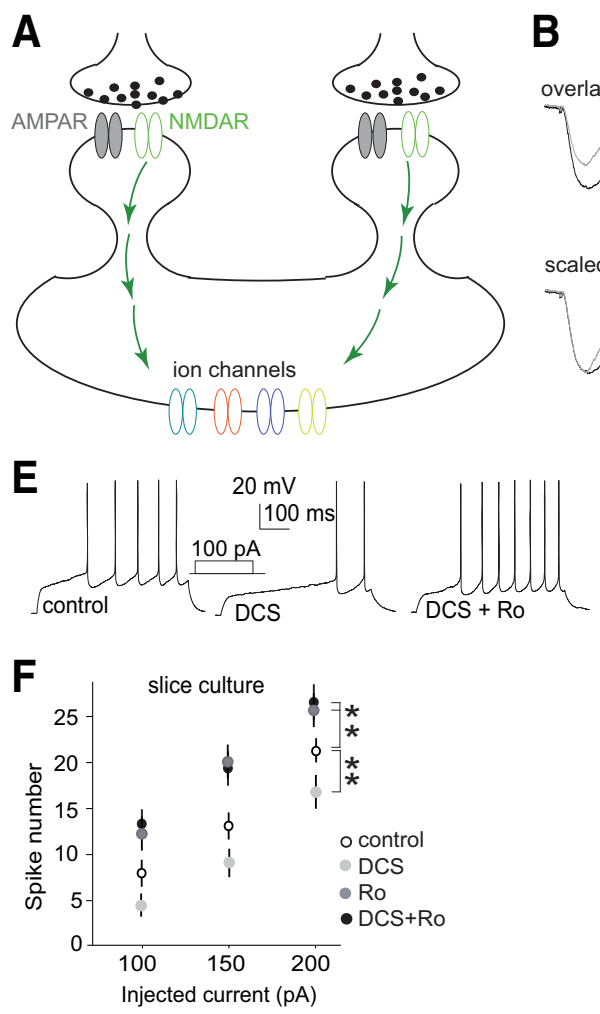

Figure 1. GluN2B NMDARs trigger synapse-to-membrane SMHC. $A$, Diagram summarizing our hypothesis that synaptic NMDARs detect increases or decreases in the excitatory synaptic strength, and regulate membrane-located ion channels through NMDAR-coupled signaling to decrease or increase the membrane excitability of NAcSh MSNs, respectively. $\boldsymbol{B}, \boldsymbol{C}$, Example traces $(\boldsymbol{B})$ and summary (C) showing that the peak amplitude of NMDAR EPSCS in NACSh MSNs in slice cultures was inhibited by perfusion of Ro256981 alone, increased by perfusion of DCS alone, and exhibited no net change in response to co-perfusion of DCS + Ro256981. B, Inset, The decay kinetics of NMDAR EPSCS (normalized) were not affected by perfusion of DCS, but became faster during co-perfusion of DCS with Ro256981. NMDAR EPSCs were recorded in this and all subsequent experiments at membrane potentials of -30 to $-40 \mathrm{mV}$ in the presence of NBQX (5 $\mu \mathrm{M})$ and picrotoxin (100 $\mu \mathrm{M}$ ). D, Diagram showing putative impact of the pharmacological manipulations on different NMDAR subtypes. In control conditions, NMDAR EPSCs are mediated by both GluN2A-and GluN2B-containing NMDARs. Perfusion of DCS enhances both GluN2A- and GluN2B-containing NMDARs, resulting in an overall increase in NMDAR EPSCs. During co-perfusion of DCS and Ro256981, GluN2B NMDARs are inhibited by R0256981, whereas GluN2A NMDARs are enhanced by DCS, with no net change in the overall amplitude of NMDAR EPSCs. $\boldsymbol{E}, \boldsymbol{F}$, Example traces $(\boldsymbol{E})$ and summary $(\boldsymbol{F})$ showing that the frequency of evoked action potentials was decreased after incubation of DCS, and increased after incubation with either Ro256981 alone, or DCS and Ro256981. G, Example images showing virally infected NAcSh MSNs in acutely prepared slices. $\boldsymbol{H}$, Example traces (top) and summary (bottom right) showing that expression of wtGluN2B or mGluN2B prolonged the decay kinetics of NMDAR EPSCS. $I, J$, Example traces $(I)$ and summary $(J)$ showing that the frequency of evoked action potentials was lower in NACSh MSNs expressing wtGluN2B, but not in MSNs expressing mGluN2B. ${ }^{*} p<0.05,{ }^{* *} p<0.01$.

Drug self-administration. Each self-administration chamber, controlled by a Med Associates system, was equipped with two nosepoke holes located $6 \mathrm{~cm}$ above the grid floor, but only one hole (active hole) activated the infusion pump. The vascular access button with a quick connecting Luer was connected with dual-Luer spring tether to a liquid swivel, which was connected to the syringe of the infusion pump. A nosepoke to the active hole resulted in a cocaine infusion $(0.75 \mathrm{mg} / \mathrm{kg}$ per infusion), accompanied by switch-on of a light within the holes, which served as conditioned stimulus (CS), and a background light. The CS stayed on for $6 \mathrm{~s}$, and the background light stayed on for $20 \mathrm{~s}$ to signal the timeout period. During this $20 \mathrm{~s}$ timeout period, additional nosepokes were counted but did not result in cocaine infusion. Poking in the inactive hole did not activate the infusion pump or elicit contingent cues, but was recorded. To avoid overdose, we set the ceiling number of drug infusions at 100 for the 12-h overnight sessions as well as the $2 \mathrm{~h}$ daily sessions. After one overnight and then $5 \mathrm{~d}$ of self-administration training $(>20$ infusion/2 h session/d), rats were placed into their home cages for withdrawal. Rats that self-administered saline (adjusted to the same volume used for cocaine infusions) were used as controls.

Preparation of NAc slice cultures and acute slices. Detailed procedures for obtaining and culturing NAc slices can be found in our previous publications (Dong et al., 2006; Huang et al., 2008). Briefly, for slice cultures, rats were deeply anesthetized with isoflurane and decapitated. Coronal NAc slices (200 $\mu \mathrm{m}$ thick; normally $2-3$ slices were obtained from each rat) were collected in ice-cold sterile low $\mathrm{Ca}^{2+}$ solution con- taining the following (in $\mathrm{mm}$ ): $126 \mathrm{NaCl}, 1.6 \mathrm{KCl}, 1.2 \mathrm{NaH}_{2} \mathrm{PO}_{4}, 1.2$ $\mathrm{MgCl}_{2}, 0.625 \mathrm{CaCl}_{2}, 18 \mathrm{NaHCO}_{3}$, and 11 glucose, and then placed on Millicell Millipore culture plate inserts in wells containing Neurobasal-A Media with 4\% B-27 and 1\% Glutamax-I Supplements (Invitrogen) for $\sim 24$ h until they were transferred to the recording media for electrophysiological recordings.

For acute slices, rats were decapitated following isoflurane anesthesia. Coronal slices $(250-300 \mu \mathrm{m})$ containing the NAc were prepared on a VT1200S vibratome (Leica) in $4^{\circ} \mathrm{C}$ cutting solution containing the following: (in mM): $135 \mathrm{~N}$-methyl-D-glucamine, $1 \mathrm{KCl}, 1.2 \mathrm{KH}_{2} \mathrm{PO}_{4}, 0.5$ $\mathrm{CaCl}_{2}, 1.5 \mathrm{MgCl}_{2}, 20$ choline- $\mathrm{HCO}_{3}$, and 11 glucose, saturated with $95 \%$ $\mathrm{O}_{2} / 5 \% \mathrm{CO}_{2}, \mathrm{pH}$ adjusted to 7.4 with $\mathrm{HCl}$. Slices were incubated in artificial CSF (aCS) containing the following (in $\mathrm{mm}$ ): $119 \mathrm{NaCl}, 2.5 \mathrm{KCl}, 2.5$ $\mathrm{CaCl}_{2}, 1.3 \mathrm{MgCl}_{2}, 1 \mathrm{NaH}_{2} \mathrm{PO}_{4}, 26.2 \mathrm{NaHCO}_{3}$, and 11 glucose), saturated with $95 \% \mathrm{O}_{2} / 5 \% \mathrm{CO}_{2}$ at $37^{\circ} \mathrm{C}$ for $30 \mathrm{~min}$ and then allowed to recover for $>30 \mathrm{~min}$ at room temperature before experimentation.

Electrophysiological recordings. Electrophysiological recordings were preferentially made from MSNs located in the medial subregion of the NAcSh. MSNs are oval-shaped and middle-sized, and therefore can be visually differentiated from local interneurons. Passive membrane properties were used as another criterion for selecting MSNs $\left(C_{\mathrm{m}} 50-150 \mathrm{pF}\right.$, $R_{\mathrm{m}} 100-400 \mathrm{~m} \Omega$ ). Interneurons could be readily distinguished by their signature electrophysiological properties, such as a relatively depolarized resting membrane potential $(\sim-72 \mathrm{mV})$, higher frequency of action potential firing upon current injection, or presence of large voltage sag at 
A

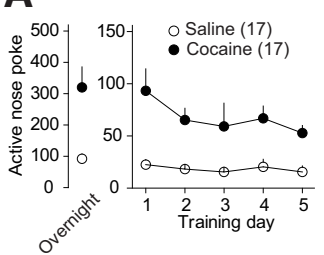

B

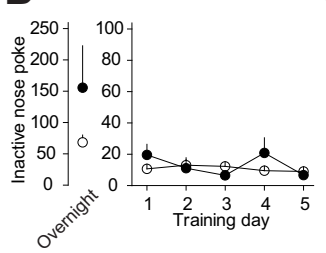

C

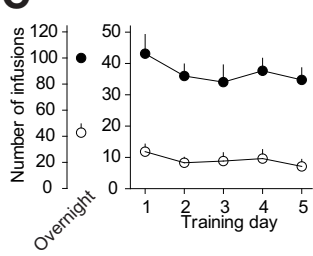

D

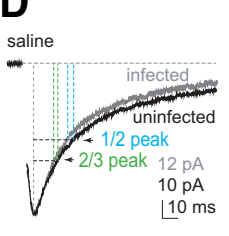

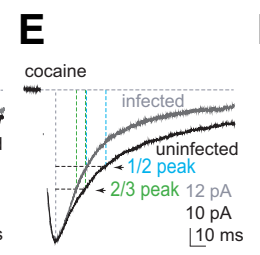

F

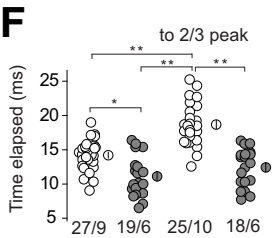

J

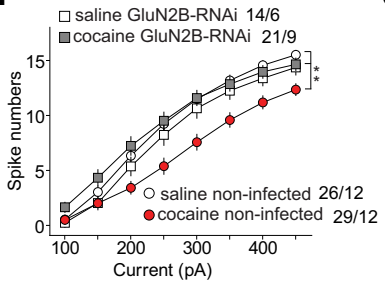

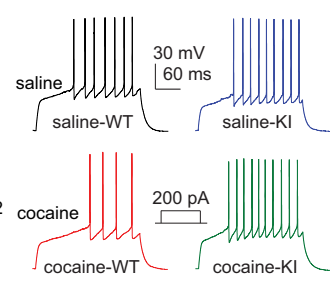

K

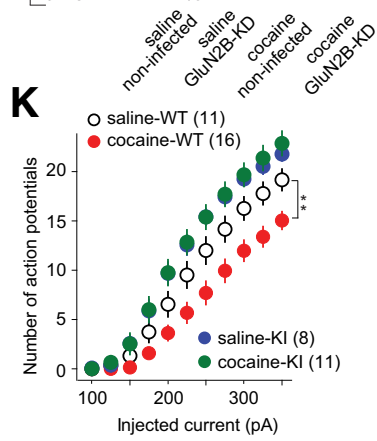

Figure 2. Preventing cocaine-induced GluN2B upregulation prevents the cocaine-induced decrease in membrane excitability of NAcSh MSNs. $A-C$, Summary of saline and cocaine selfadministration training data for rats used in $\boldsymbol{D}-\boldsymbol{I}$ and Figure $3 \boldsymbol{A}$ and $\boldsymbol{B}$. $\boldsymbol{D}-\boldsymbol{G}$, Example traces $(\boldsymbol{D}, \boldsymbol{E})$ and summaries $(\boldsymbol{F}, \boldsymbol{G})$ showing that the normally observed cocaine-induced increase in the decay kinetics of NMDAR EPSCs was prevented in GluN2B-RNAi-expressing NACSh MSNs. $\boldsymbol{H}, \boldsymbol{I}$, Example traces $(\boldsymbol{H})$ and summary $(\boldsymbol{I})$ showing that the membrane excitability of NAcSh MSNs was decreased after $1 \mathrm{~d}$ of withdrawal from cocaine self-administration, whereas preventing cocaine-induced upregulation of synaptic GluN2B-containing NMDARs by viral-mediated expression of GluN2B-RNAi prevented this membrane adaptation. $\boldsymbol{J}, \boldsymbol{K}$, Example traces $(\boldsymbol{J})$ and summary $(\boldsymbol{K})$ showing that in GluN2B-KI mice in which the interaction between GluN2B and CaMKII was disrupted, repeated cocaine administration no longer decreased the membrane excitability of NACSh MSNs. ${ }^{*} p<0.05,{ }^{* *} p<0.01$.

hyperpolarized potentials. Interneurons were excluded from data analysis.

During recordings, slices were superfused with aCSF that was heated to $30-32^{\circ} \mathrm{C}$ by passing the solution through a in-line heater (Warner) before it entered the chamber. To measure the membrane excitability, electrodes $(2-5 \mathrm{M} \Omega)$ were filled with a potassium-based internal solution (in mM: $130 \mathrm{KMeSO}_{3}, 10 \mathrm{KCl}, 0.4$ EGTA, 10 HEPES, $2.5 \mathrm{Mg}$-ATP, 0.25 $\mathrm{Na}-\mathrm{GTP}, 2 \mathrm{MgCl}_{2}-6 \mathrm{H}_{2} \mathrm{O}, \mathrm{pH}$ 7.3). To record EPSCs, electrodes were filled with a cesium-based internal solution (in mM: $140 \mathrm{CsCH}_{3} \mathrm{O}_{3} \mathrm{~S}, 5$ TEA-Cl, 0.4 Cs-EGTA, 20 HEPES, 2.5 Mg-ATP, 0.25 Na-GTP, 1 QX-314, $\mathrm{pH}$ 7.3). To record AMPAR EPSCs, picrotoxin $(100 \mu \mathrm{M})$ was included in the recording bath to inhibit $\mathrm{GABA}_{\mathrm{A}}$ receptor-mediated currents. To record NMDAR EPSCs, both picrotoxin and NBQX (5 $\mu \mathrm{M})$ were included to inhibit $\mathrm{GABA}_{\mathrm{A}}$ receptor- and AMPAR-mediated currents. Presynaptic afferents were stimulated by a constant-current isolated stimulator (Digitimer), using a monopolar electrode. Series resistance was left uncompensated but monitored continuously during recording. Cells with a change in series resistance beyond $15 \%$ were not accepted for data analysis. Synaptic currents were recorded with a MultiClamp 700B amplifier, filtered at $2.6-3 \mathrm{kHz}$, amplified five times, and then digitized at $20 \mathrm{kHz}$.

Only electrophysiologically "stable" neurons were included for data analysis. In experiments measuring the membrane excitability, after forming the whole-cell current-clamp configuration, the recorded cells were given $\sim 5 \mathrm{~min}$ for stabilization (oscillations $<5 \mathrm{mV}$ ) of their resting membrane potentials. Recordings were discontinued if cells failed to meet this criterion. After the stabilization period, the resting membrane potential was adjusted to $-80 \mathrm{mV}$ by injecting a small current (usually $<30 \mathrm{pA}$ ). A current step protocol (from -200 to $+450 \mathrm{pA}$, with a $50 \mathrm{pA}$ increment; interpulse interval, $15 \mathrm{~s}$ ) was then repeated at least three times. Immediately after the recording of a particular cell, the number of evoked action potentials was compared across all three runs. Cells with a run-up or run-down of $>15 \%$ were excluded from further analysis. Thus, only MSNs with stable resting membrane potential and stable evoked action potential firing were included in the final analysis. The afterhyperpolarization potential (AHP) was sampled following the first action potential elicited by the $300 \mathrm{pA}$ current injection. The threshold of action potential was defined as the membrane potential at which the $d V / d t$ reached 10 before the spike. The amplitude of the fAHP was defined as the voltage difference between the action potential threshold and the lowest hyperpolarization point after the action potential. The mAHP was defined as the difference of the membrane potentials between the action potential threshold and $10 \mathrm{~ms}$ after the action potential threshold.

Drugs. D-APV and NBQX were purchased from Tocris Bioscience. All other chemicals were purchased from Sigma-Aldrich.

Data acquisition and statistics. All data were analyzed off-line. More than $75 \%$ of the data were analyzed blind to experimental group. Normal distribution was assumed for all data collected. All descriptive results were presented as mean \pm SEM. A two-tail $t$ test, paired $t$ test, or ANOVA was used for statistical comparisons as specified in the text. Bonferroni post-test was performed if ANOVA indicated significance. No data points were excluded unless specified in the text. For experiments in which the endpoints were behavioral results (see Fig. 7), animal-based statistics were presented. For experiments in which the endpoints were from individual cells, both animal- and cell-based statistical analyses were performed, and these results were highly consistent. For animalbased statistics, we used the averaged value of a parameter from all cells recorded from an animal to represent the parameter of this animal. In cell-based analyses, sample sizes were presented as $n / m$, in which $n$ represented the number of cells, and $m$ represented the number of animals from which cells were collected.

\section{Results}

GluN2B-CaMKII signaling as the synaptic sensor of SMHC

AMPARs mediate the majority of excitatory synaptic transmission and AMPAR-mediated currents are often used as a measure of excitatory synaptic strength. We previously demonstrated a form of synapse-to-membrane homeostatic plasticity in NAcSh MSNs in which an increase or decrease in the AMPAR-mediated excitatory synaptic strength induced a homeostatic decrease or increase in the membrane excitability, respectively (Ishikawa et al., 2009; Fig. 1A). We termed this and the potential reverse form (i.e., membrane-to-synapse) of homeostatic plasticity SMHC.

For an effective homeostatic feedback loop, the minimum requirements are a detector of alterations, an effector to make compensatory changes, and a signaling pathway that links the detector to the effector. Our previous results identified synaptic NMDA receptors (NMDARs) as the detectors of excitatory synaptic strength, based on evidence that inhibiting NMDARs prevents synapse-to-membrane homeostatic plasticity, whereas 
persistently increasing or decreasing NMDAR function without affecting synaptic AMPARs is sufficient to induce homeostatic decreases or increases in the membrane excitability of NAcSh MSNs (Ishikawa et al., 2009). However, it remains unclear which subtypes of NMDARs and which signaling pathways are involved.

In the rodent forebrain, NMDARs can be largely divided into two categories, GluN2B-containing versus GluN2B-lacking NMDARs, each with unique intracellular signaling properties (Monyer et al., 1994; Cull-Candy and Leszkiewicz, 2004). To evaluate the roles of these two NMDAR subtypes in synapse-tomembrane homeostatic plasticity, we used a set of pharmacological manipulations in NAcSh slice cultures (Fig. $1 B-D$ ). In our experimental condition, NMDAR-mediated EPSCs were evoked at $-40 \mathrm{mV}$ in the presence of the AMPAR-selective antagonist NBQX $(5 \mu \mathrm{M})$; these EPSCs are presumably mediated by both GluN2B-containing and GluN2B-lacking NMDARs. Application of the GluN2B-selective antagonist Ro256981 (20 nM) decreased the amplitude and shortened the decay kinetics of NMDAR EPSCs, as expected based on properties of GluN2B NMDARs (Fig. $1 B-D$ ). D-cycloserine (DCS) is an NMDAR glycine-site agonist, and therefore enhances the function of both GluN2Bcontaining and GluN2B-lacking NMDARs. Application of DCS $(10 \mu \mathrm{M})$ alone increased the amplitudes of NMDAR EPSCs (Fig. $1 B-D)$. When DCS and Ro256981 were coapplied, the overall amplitude of NMDAR EPSCs returned to the control level. This "lack" of change in the overall amplitude of NMDAR EPSCs likely resulted because the DCS-mediated increase in the GluN2B-lacking NMDAR component was offset by the Ro256981-mediated decrease in the GluN2B-containing NMDAR component $\left(F_{(2,14)}=\right.$ $21.0, p<0.01$, one-way ANOVA repeated measure; $p=0.02$, control vs DCS; $p=0.03$, DCS vs DCS + Ro256981, Bonferroni post-test; Fig. 1B-D). Thus, coapplication of DCS and Ro256981 creates an experimental condition in which NMDARs are simultaneously manipulated in three different ways: (1) no change in the overall NMDAR activity, (2) upregulation of GluN2B-lacking NMDAR function, and (3) downregulation of GluN2B-containing NMDAR function (Fig. 1D).

We used this coapplication strategy to gain insight into which NMDAR subtype acts as the sensor of synapse-to-membrane homeostatic plasticity. If the total synaptic NMDAR activity is the key regardless of the contributing NMDAR subtypes, coincubation of DCS and Ro256981, which did not significantly affect the total NMDAR activity, should not induce any homeostatic change in membrane excitability. If GluN2B-lacking NMDARs are the key, an increase in this component through coapplication of DCS and Ro256981 should induce a homeostatic decrease in the membrane excitability. Conversely, if GluN2B-containing NMDARs are the key, a decrease in this component by coincubation of DCS and Ro256981 should induce a homeostatic increase in the membrane excitability. Similar to previous results, after an overnight $(\sim 12 \mathrm{~h})$ incubation of the NAcSh slice cultures with DCS alone, we observed a decrease in the membrane excitability of NAcSh MSNs (Fig. 1E, F; see statistics in next sentence). In contrast, overnight incubation with either Ro 256981 alone or coincubation of DCS and Ro256981 induced a similar increase in the membrane excitability of NAcSh MSNs $\left(F_{(2,75)}=45.7, p<\right.$ 0.01 , two-way ANOVA; $p<0.01$, control vs DCS, control vs Ro256981, or control vs DCS + Ro256981, Bonferroni post-test; Fig. $1 E, F)$. These results support the scenario in which GluN2B, but not GluN2A, NMDARs mediate the synapse-to-membrane homeostatic plasticity in NAcSh MSNs. Note that acute pharmacological manipulations of NMDARs did not change the membrane excitability of NAcSh MSNs (Ishikawa et al., 2009), suggesting that this NMDAR-mediated synapse-to-membrane homeostatic plasticity happens gradually.

Enlightened by the above pharmacological results, we next used molecular tools to scrutinize synaptic GluN2B and its coupled signaling during synapse-to-membrane homeostatic plasticity. At the signaling level, GluN2B differs from GluN2A in its ability to bind and recruit activated calcium-calmodulindependent protein kinase II (CaMKII), thereby promoting the maintenance of CaMKII activation (Strack and Colbran, 1998; Leonard et al., 1999; Strack et al., 2000; Mayadevi et al., 2002; Halt et al., 2012). We used viral-mediated gene transfer to express a mutant form of GluN2B (mGluN2B). This mGluN2B shares all other biophysical properties with wild-type GluN2B (wtGluN2B), including slow decay kinetics, but its CaMKII interacting site is compromised (Barria and Malinow, 2005). Expression of wtGluN2B was the control condition. One day after virus injection, many NAcSh MSNs were infected to express targeted genes, as indicated by GFP expression (Fig. $1 G$ ). NMDAR EPSCs in both wtGluN2B- and mGluN2B-expressing MSNs exhibited increased decay kinetics, indicating that virally expressed wtGluN2B or mGluN2B subunits were assembled into functional synaptic NMDARs (decay kinetics was measured as the time required for NMDAR-mediated EPSCs to decrease from peak amplitude to $1 / 2$ peak amplitude: $F_{(2,35)}=6.2, p=0.01$, one-way ANOVA; $p<$ 0.05 control vs wtGluN2B or mGluN2B, Bonferroni post-test; Fig. $1 H$ ). Note that due to the complicated decay properties of NMDAR EPSCs in NAcSh MSNs, we chose to use the time elapsed from the peak EPSCs to $2 / 3$ or $1 / 2$ of the peak amplitude of EPSCs to assess the decay kinetics (Huang et al., 2009). Importantly, the membrane excitability of wtGluN2B-expressing NAcSh MSNs was decreased compared with MSNs that expressed GFP alone $\left(F_{(2,33)}=7.5, p<0.01\right.$, two-way ANOVA; $p<$ 0.01 control vs wtGluN2B, Bonferroni post-test; Fig. $1 I, J)$. These molecular results, together with above pharmacological results, indicate that upregulation of GluN2B NMDARs is sufficient to induce a homeostatic decrease in the membrane excitability. In contrast, the membrane excitability was not altered in mGluN2Bexpressing MSNs ( $p>0.99$, control vs mGluN2B, Bonferroni post-test; Fig. $1 H$ ), suggesting that loss of CaMKII-signaling abrogates GluN2B NMDAR-mediated synapse-to-membrane homeostatic plasticity.

\section{GluN2B-CaMKII signaling initiates synapse-to-membrane homeostatic dysregulation after cocaine}

After short-term (1-2 d) withdrawal from either repeated intraperitoneal injections of cocaine or cocaine self-administration, the overall excitatory synaptic strength in NAc MSNs, which is primarily mediated by synaptic AMPARs, is not significantly altered (Boudreau and Wolf, 2005; Kourrich et al., 2007; Conrad et al., 2008). Our previous results show that repeated intraperitoneal injections of cocaine induce an upregulation of synaptic GluN2B NMDARs in NAcSh MSNs, which results from activation of CREB, one of the earliest molecular effects of cocaine (Huang et al., 2009; Brown et al., 2011). Similarly, our present study detected prolonged decay kinetics of NMDAR EPSCs in NAcSh MSNs $1 \mathrm{~d}$ after discontinuing cocaine self-administration, suggesting a similar increase in synaptic GluN2B NMDARs (Fig. $2 A-G$; see statistics in next paragraph). Thus, although the actual AMPAR-mediated excitatory synaptic strength is not altered at this withdrawal time point, cocaine-induced upregulation of GluN2B NMDARs may create a false homeostatic signal, triggering synapse-to-membrane homeostatic plasticity to decrease the membrane excitability of NAcSh MSNs. Consistent with this sce- 
nario, the membrane excitability of NAcSh MSNs is decreased after short-term (1-2 d) withdrawal from either noncontingent or contingent cocaine administration (Zhang et al., 1998; Dong et al., 2006; Ishikawa et al., 2009; Mu et al., 2010; Kourrich et al., 2013).

To examine whether upregulation of GluN2B NMDARs plays a causal role in decreasing the membrane excitability of NAcSh MSNs in cocaine-exposed rats, we designed a GluN2B-RNAi, which, after viral-mediated expression, shortened the decay kinetics of NMDAR EPSCs in NAcSh MSNs in saline-exposed rats, demonstrating in vivo knockdown efficacy (Fig. $2 D-G$; see statistics in next sentence). Knocking-down GluN2B prevented the cocaine-induced increase in decay kinetics of NMDAR EPSCs, thus validating this RNAi as an effective tool preventing cocaine-induced GluN2B upregulation (time to $2 / 3$ and $1 / 2$ peak: $F_{(1,85)}=6.9$ and $6.8, p=0.01$ and 0.01 , cell-based two-way ANOVA; $p<0.01$ and 0.01 salinenoninfected vs saline GluN2B-RNAi, $p<0.01$ and 0.01 cocainenoninfected vs cocaine GluN2B-RNAi, Bonferroni post-test; $F_{(1,27)}$ $=4.5$ and $4.2, p=0.042$ and 0.049 , animal-based ANOVA; $p<0.01$ and 0.01 cocaine-noninfected vs saline-noninfected, $p<0.01$ and 0.01 cocaine-noninfected vs cocaine-GluN2B-RNAi, $p=0.03$ and 0.13 saline-noninfected vs saline-GluN2B-RNAi, Bonferroni posttest; Fig. $2 D-G)$. We then examined the membrane excitability. In control (noninfected) MSNs, the membrane excitability was decreased after $1 \mathrm{~d}$ of withdrawal from cocaine self-administration (Fig. 2 H, I; see statistics below), similar to previous results (Mu et al., 2010). This cocaine-induced membrane adaptation was prevented in NAcSh MSNs expressing GluN2B-RNAi $\left(F_{(1,86)}=11.0, p<0.01\right.$, cell-based three-way mixed ANOVA with repeated-measures injected current 200, 250, 300, 350, 400, and 450 pA; $p<0.01$ salinenoninfected vs cocaine-noninfected $p<0.01$ cocaine-noninfected vs cocaine-GluN2B-RNAi, Bonferroni post-test; $F_{(1,35)}=10.1, p<$ 0.01, animal-based ANOVA; $p<0.01$ cocaine-noninfected vs cocaine-GluN2B-RNAi, $p>0.99$ saline-noninfected vs salineGluN2B-RNAi, $p>0.99$ saline-GluN2B-RNAi vs cocaine-GluN2BRNAi, Bonferroni post-test; Fig. $2 \mathrm{H}, \mathrm{I}$ ). These results suggest that synaptic upregulation of GluN2B NMDARs is essential for the cocaine-induced decrease in membrane excitability of NAcSh MSNs.

To delineate the role of GluN2B-coupled CaMKII-signaling, we used a knock-in (KI) mouse line, in which the endogenous GluN2B was replaced by a mutant with reduced ability to activate CaMKII signaling, and thus, conceivably, with reduced basal GluN2B-CaMKII signaling (Halt et al., 2012). Due to the technical difficulties associated with self-administration in mice, we used the $5 \mathrm{~d}$ intraperitoneal injection procedure, which also results in synaptic upregulation of GluN2B and decreased membrane excitability of NAcSh MSNs (Huang et al., 2009; Ishikawa et al., 2009; Mu et al., 2010; Brown et al., 2011). Compared with WT mice, NAcSh MSNs in KI mice exhibited increased membrane excitability after saline (control) administration, suggesting that decreased basal GluN2B-CaMKII signaling is sufficient to induce synapse-to-membrane $\operatorname{SMHC}\left(F_{(1,42)}=4.3, p=0.04\right.$, cell-based three-way mixed ANOVA with repeated measures over injected current: 200, 225, 250, 275, and $300 \mathrm{pA} ; p=0.04$ WT-saline vs WT-cocaine, Bonferroni post-test; $F_{(1,11)}=5.3, p=$ 0.04 , animal-based ANOVA; $p=0.02 \mathrm{WT}$-cocaine vs WT-saline, $p<0.01 \mathrm{WT}$-cocaine vs GluN2B KI-cocaine, $p=0.64 \mathrm{WT}$-saline vs GluN2B KI-saline, Bonferroni post-test; Fig. 2J,K). Furthermore, in these mutant mice, exposure to cocaine could no longer induce a decrease in membrane excitability of NAcSh MSNs ( $p=$ $0.21 \mathrm{WT}$-saline vs KI-cocaine, $p>0.99 \mathrm{KI}$-saline vs KI-cocaine, Bonferroni post-test; Fig. $2 J, K)$.
Collectively, these results support the hypothesis that cocaineinduced upregulation of synaptic GluN2B NMDARs creates a false signal that inappropriately engages SMHC, resulting in decreased membrane excitability of NAcSh MSNs.

\section{GluN2B-to-SK2 channels in cocaine-induced SMHC}

The SK2 type of calcium-activated potassium channel mediates the medium component of the afterhyperpolarization potential (mAHP), which transiently hyperpolarizes the cell membrane after action potentials to delay the generation of subsequent action potentials. The SK2-mediated $\mathrm{mAHP}$ in NAcSh MSNs is low in naive or saline-exposed rats, but is increased after repeated intraperitoneal injections of cocaine, contributing to the decreased membrane excitability of NAcSh MSNs (Ishikawa et al., 2009). Similarly, $1 \mathrm{~d}$ after discontinuing cocaine self-administration $(0.75 \mathrm{mg} / \mathrm{kg}$ per infusion, 1 overnight followed by $2 \mathrm{~h} / \mathrm{d} \times 5 \mathrm{~d}$; Fig. 2A-C), control (noninfected) NAcSh MSNs exhibited increased mAHP amplitudes (Fig. $3 A, B$; see statistics in next paragraph).

To determine whether SK2 is the target for GluN2B-mediated depression of membrane excitability after cocaine, we virally expressed GluN2B-RNAi $\sim 2$ weeks before the self-administration training. Cocaine-induced upregulation of $\mathrm{mAHP}$ was prevented in NAcSh MSNs expressing GluN2B-RNAi, tested $1 \mathrm{~d}$ after discontinuing cocaine self-administration $\left(F_{(1,86)}=10.6, p<0.01\right.$, cell-based two-way ANOVA; $p<0.01$ cocaine-noninfected vs saline-noninfected, $p<0.01$ cocaine-noninfected vs cocaineGluN2B-RNAi, Bonferroni post-test; $F_{(1,35)}=6.8, p=0.01$, animal-based ANOVA; $p<0.01$ cocaine-noninfected vs salinenoninfected, $p<0.01$ cocaine-noninfected vs cocaine-GluN2BRNAi, $p>0.99$ saline-noninfected vs saline-GluN2B-RNAi, $p>$ 0.99 saline-GluN2B-RNAi vs cocaine-GluN2B-RNAi, Bonferroni post-test; Fig. $3 A, B)$. Furthermore, cocaine-induced upregulation of the MAHP in NAcSh MSNs persisted after $45 \mathrm{~d}$ of drug withdrawal, and this long-lasting effect was also prevented by pretraining expression of GluN2B-RNAi $\left(F_{(1,97)}=4.4, p=\right.$ 0.04 , cell-based two-way ANOVA; $p=0.03$ saline-noninfected vs cocaine-noninfected, $p<0.01$ cocaine-noninfected vs cocaineGluN2B-RNAi, Bonferroni post-test; $F_{(1,35)}=5.4, p=0.03$ animal-based ANOVA; $p=0.02$ cocaine-noninfected vs salinenoninfected, $p<0.01$ cocaine-noninfected vs cocaine-GluN2BRNAi, Bonferroni post-test; Fig. 3C-E). Consistently, the membrane excitability of NAcSh MSNs remained low after $45 \mathrm{~d}$ of withdrawal from cocaine, and this long-lasting membrane effect was prevented by pre-expression of GluN2B-RNAi $\left(F_{(1,97)}=\right.$ 11.2, $p<0.01$, cell-based three-way mixed ANOVA with repeated measures; $p<0.01$ saline-noninfected vs cocainenoninfected, $p<0.01$ cocaine-noninfected vs cocaine-GluN2BRNAi, Bonferroni post-test; $F_{(1,35)}=11.6, p<0.01$, animalbased ANOVA; $p<0.01$ cocaine-noninfected vs salinenoninfected, $p<0.01$ cocaine-noninfected vs cocaine-GluN2BRNAi, $p>0.99$ saline-noninfected vs saline-GluN2B-RNAi, $p>$ 0.99 saline-GluN2B-RNAi vs cocaine-GluN2B-RNAi, Bonferroni post-test; Fig. $3 F, G)$. Thus, SK2 channels are potential downstream effectors of GluN2B/CaMKII-signaling and key for the expression of SMHC-mediated decreases in membrane excitability after cocaine exposure.

To manipulate SK2 channels, we made an adeno-associated virus 2 pseudotyped with AAV2/8 that expressed SK2-RNAi. Because of the low basal levels of SK2 channels in NAcSh MSNs (Ishikawa et al., 2009), we functionally validated this virus using dorsal striatal MSNs, which expressed higher basal levels of SK2 and a more robust $\mathrm{mAHP}$. The mAHP amplitude was signifi- 

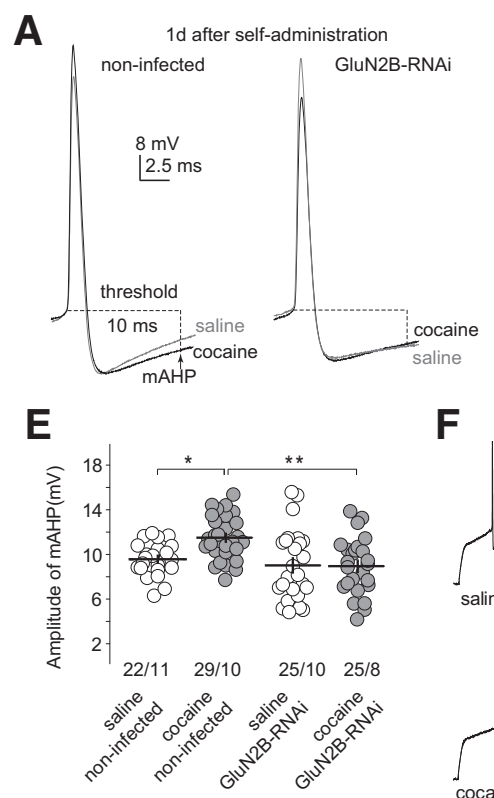
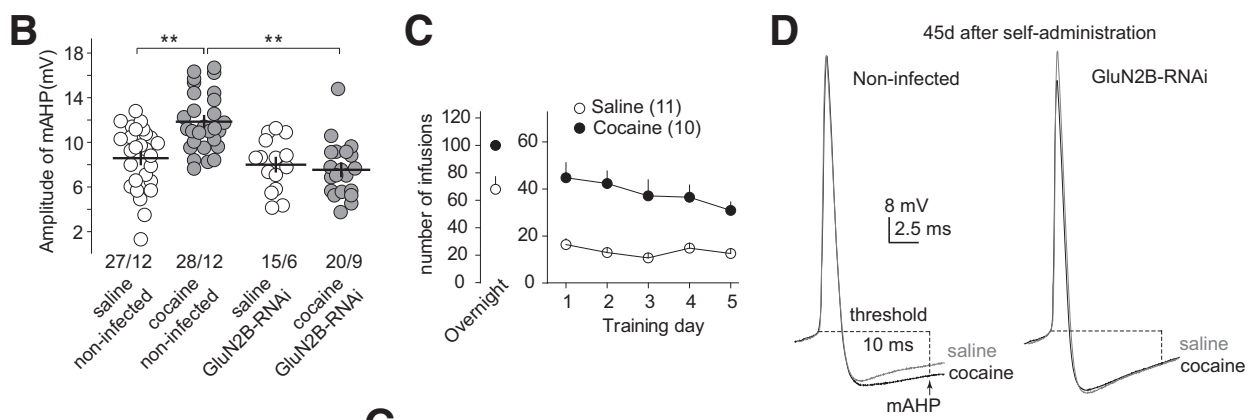

$\mathbf{F}$

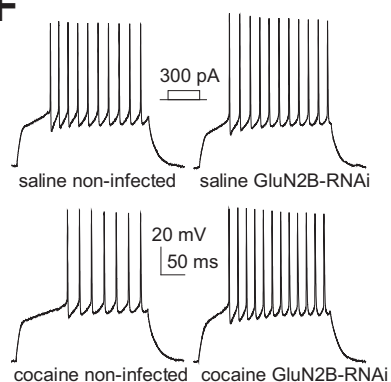

G

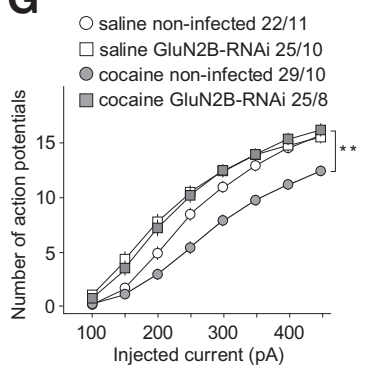

Figure 3. SK2 is the effector of cocaine-induced synapse-to-membrane homeostatic dysregulation. $\boldsymbol{A}, \boldsymbol{B}$, Example traces $(\boldsymbol{A})$ and summary $(\boldsymbol{B})$ showing that the mAHP in NAcSh MSNs was increased after $1 \mathrm{~d}$ of withdrawal from cocaine self-administration, and this cocaine-induced membrane adaptation was prevented in MSNs expressing GluN2B-RNAi. $C$, Summary of saline and cocaine self-administration training data for rats used for $\boldsymbol{D}-\boldsymbol{G} . \boldsymbol{D}, \boldsymbol{E}$, Example traces $(\boldsymbol{D})$ and summary $(\boldsymbol{E})$ showing that the $\mathrm{mAHP}$ in NAcSh MSNs was increased after $45 \mathrm{~d}$ of withdrawal from cocaine self-administration, and this cocaine-induced membrane adaptation was prevented in MSNs expressing GluN2B-RNAi. $\boldsymbol{F}, \mathbf{G}$, Example traces $(\boldsymbol{F})$ and summary $(\boldsymbol{G})$ showing that the cocaine-induced decrease in membrane excitability persisted after $45 \mathrm{~d}$ of withdrawal from cocaine self-administration, and this cocaine-induced membrane adaptation was prevented in NAcSh MSNs infected by GluN2B-RNAi-expressing virus. ${ }^{*} p<0.05,{ }^{* *} p<0.01$.
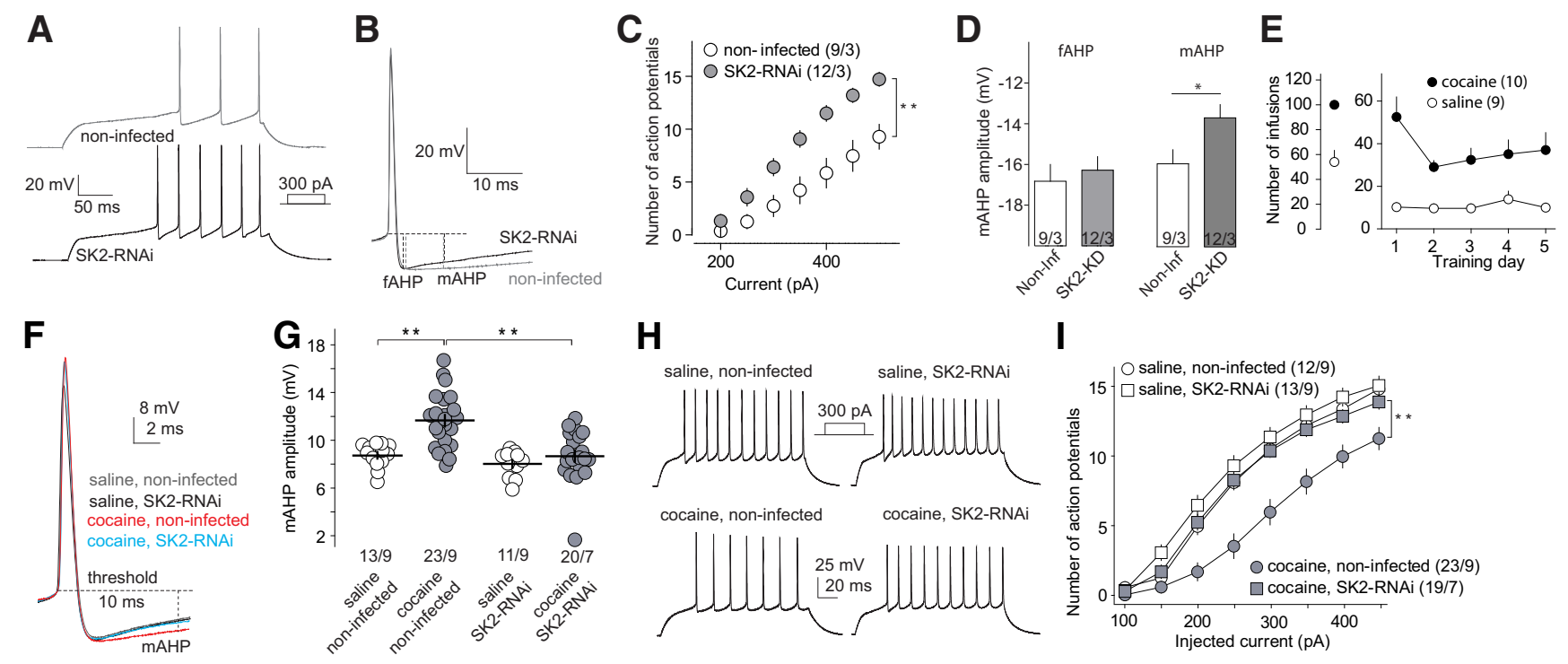

Figure 4. Preventing upregulation of SK2 prevents the cocaine-induced decrease in membrane excitability. $A, B$, Example traces showing evoked action potential firing and mAHP in SK2-RNAiexpressing MSNs in the dorsal striatum. C, D, Summaries showing that expression of SK2-RNAi increased the frequency of evoked action potentials and decreased the amplitude of the mAHP without affecting the fAHP. $\boldsymbol{E}$, Summary of the self-administration results of rats used in $\boldsymbol{F}-\boldsymbol{I} . \boldsymbol{F}, \boldsymbol{G}$, Example traces $(\boldsymbol{F})$ and summary $(\boldsymbol{G})$ showing that the cocaine-induced increase in the $\mathrm{mAHP}$ was prevented in NACSh MSNs infected by SK2-RNAi-expressing virus tested $1 \mathrm{~d}$ after self-administration. $\boldsymbol{H}, \boldsymbol{I}$, Example traces $(\boldsymbol{H})$ and summary $(\boldsymbol{I})$ showing that the cocaine-induced decrease in membrane excitability was prevented in NAcSh MSNs infected by SK2-RNAi-expressing virus. ${ }^{*} p<0.05,{ }^{*} p<0.01$.

cantly decreased in striatal MSNs that expressed SK2-RNAi $\left(t_{(19)}=2.4, p=0.03\right.$, cell-based two-tailed $t$ test; Fig. $\left.4 A-D\right)$, whereas the fAHP was unaffected $\left(t_{(19)}=0.52, p=0.61\right.$, cellbased two-tailed $t$ test), suggesting an effective and selective knockdown of SK2. We then virally expressed this SK2-RNAi in the NAcSh before self-administration training. One day after discontinuing saline self-administration, SK2-RNAi-expressing and noninfected NAcSh MSNs exhibited similarly low mAHP ampli- tudes, confirming that the basal level of SK2 was low in NAcSh MSNs and could not be further decreased (Fig. 4F, G; see statistics below). On the other hand, expression of SK2-RNAi effectively prevented the upregulation of $\mathrm{mAHP}$ in cocaine-exposed rats on the first day of withdrawal $\left(F_{(1,63)}=4.5, p=0.04\right.$, cell-based two-way ANOVA; $p<0.01$ cocaine-noninfected vs salinenoninfected, $p<0.01$ cocaine-noninfected vs cocaine-SK2RNAi, $p>0.99$ saline-noninfected vs saline-SK2-RNAi, 
A

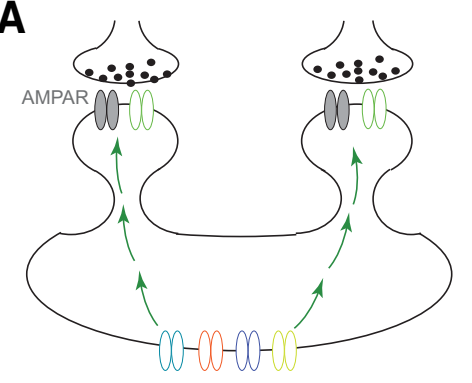

B

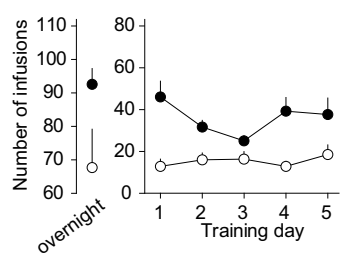

C

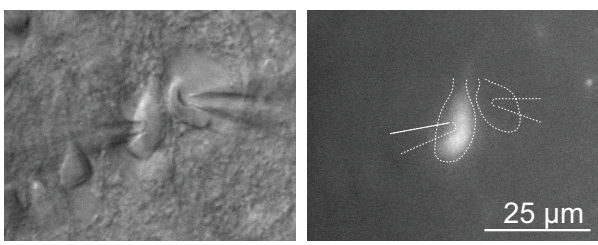

D
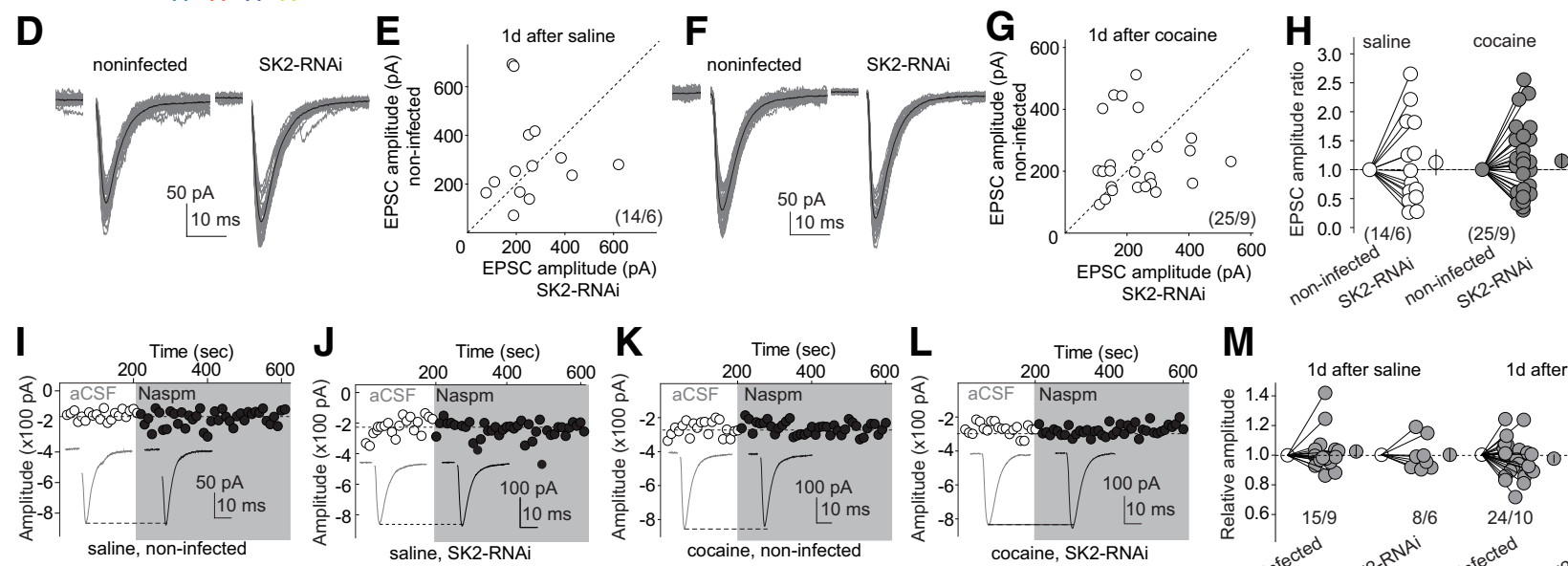

SK2-RNA

M

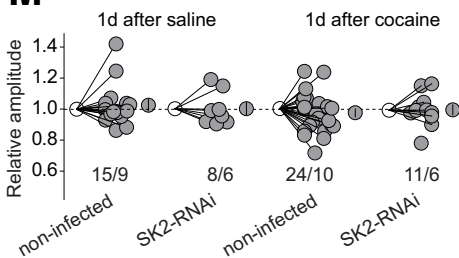

Figure 5. Preventing the cocaine-induced upregulation of SK2 does not affect excitatory synaptic strength in NAcSh MSNs after $1 \mathrm{~d}$ of withdrawal. $\boldsymbol{A}$, Diagram showing the hypothetical membrane-to-synapse homeostatic crosstalk: changes in the membrane excitability induce compensatory changes in the overall strength of excitatory synapses. $\boldsymbol{B}$, Summary of self-administration training data for rats used in $\mathbf{D}-\mathbf{M}$. C, Images showing the pairwise recording setup, in which a virally infected MSN and its neighboring noninfected MSN are simultaneously recorded in response to the same presynaptic stimulation. $\boldsymbol{D}$, Example traces simultaneously recorded from an SK2-RNAi-expressing and a noninfected neighboring MSN from a saline-exposed rat. $\boldsymbol{E}$, Amplitudes of AMPAR EPSCS of MSNs expressing SK2-RNAi versus those of simultaneously recorded noninfected MSNs in saline-exposed rats. $\boldsymbol{F}$, Example traces simultaneously recorded from an SK2-RNAiexpressing and a noninfected neighboring MSN from a cocaine-exposed rat. G, Amplitudes of AMPAR EPSCs of MSNs expressing SK2-RNAi versus those of simultaneously recorded noninfected MSNs in cocaine-exposed rats. $\boldsymbol{H}$, Summary showing that after $1 \mathrm{~d}$ of withdrawal from self-administration, preventing the cocaine-induced decrease in membrane excitability did not affect excitatory synaptic strength in NACSh MSNs. $I-M$, Example trials $(\boldsymbol{I}-\boldsymbol{L})$ and $(\boldsymbol{M})$ summary showing that $1 \mathrm{~d}$ after self-administration, the Naspm sensitivity of AMPAR EPSCs is not different between noninfected MSNs and SK2-RNAi expressing MSNs in both saline- and cocaine-exposed rats.

Bonferroni post-test; $F_{(1,30)}=7.6, p=0.01$, animal-based ANOVA; $p<0.01$ cocaine-noninfected vs saline-noninfected, $p<0.01$ cocaine-noninfected vs cocaine-SK2-RNAi, $p=0.17$ saline-noninfected vs saline-SK2-RNAi, $p=0.33$ saline-SK2RNAi vs cocaine-SK2-RNAi, Bonferroni post-test; Fig. 4F, G). Furthermore, expression of SK2-RNAi did not affect basal membrane excitability of NAcSh MSNs, as shown in saline-exposed rats, but prevented the cocaine-induced decrease in their membrane excitability $\left(F_{(1,63)}=4.5, p=0.04\right.$, cell-based three-way mixed ANOVA with repeated measures over injected current of 200, $250,300,350,400$, and $450 \mathrm{pA} ; p<0.01$ cocaine-noninfected vs saline-noninfected, $p<0.01$ cocaine-noninfected vs cocaineSK2-RNAi, $p>0.99$ saline-noninfected vs saline-SK2-RNAi, Bonferroni post-test; $F_{(1,30)}=6.7, p=0.02$ animal-based ANOVA; $p<0.01$ cocaine-noninfected vs saline-noninfected, $p<0.01$ cocaine-noninfected vs cocaine-SK2-RNAi, $p=0.48$ saline-noninfected vs saline-SK2-RNAi, $p>0.99$ saline-SK2RNAi vs cocaine-SK2-RNAi, Bonferroni post-test; Fig. 4H,I). Thus, the SK2 channel is likely one of the key ion channels that are changed after cocaine administration to decrease the membrane excitability.

\section{Membrane-to-synapse SMHC during withdrawal from cocaine}

The above results demonstrate a synapse-to-membrane SMHC and suggest that it is hijacked by cocaine to decrease the mem- brane excitability of NAcSh MSNs. Next, we asked whether SMHC also exists in the membrane-to-synapse direction and contributes to synaptic alterations after withdrawal from cocaine. A critical adaptation at NAcSh excitatory synapses after longterm withdrawal from cocaine self-administration is the delayed upregulation of synaptic strength (Wolf, 2016). Specifically, synaptic AMPARs in NAc MSNs largely remain at the basal level (saline controls) $1 \mathrm{~d}$ after cocaine self-administration. When cocaine withdrawal proceeds, excitatory synapses in both the shell and core subregions of the NAc are gradually strengthened by recruiting CP AMPARs (Wolf, 2016). A long-held question is what mechanisms drive AMPARs toward NAc excitatory synapses during cocaine withdrawal, during which no apparent external stimuli are present to induce Hebbian plasticity. We hypothesize that the decreased membrane excitability in early withdrawal from cocaine self-administration initiates a membraneto-synapse SMHC process, which gradually develops as withdrawal continues, leading to the strengthening of excitatory synapses after long-term withdrawal (Fig. 5A).

The above hypothesis predicts that preventing the cocaineinduced decrease in the membrane excitability will prevent upregulation of synaptic AMPARs after long-term withdrawal from cocaine. To test this prediction, we performed a pairwise recording to simultaneously measure EPSCs in a noninfected NAcSh MSN and a neighboring SK2-RNAi-expressing MSN after cocaine self-administration (Fig. 5B,C). We started with two 

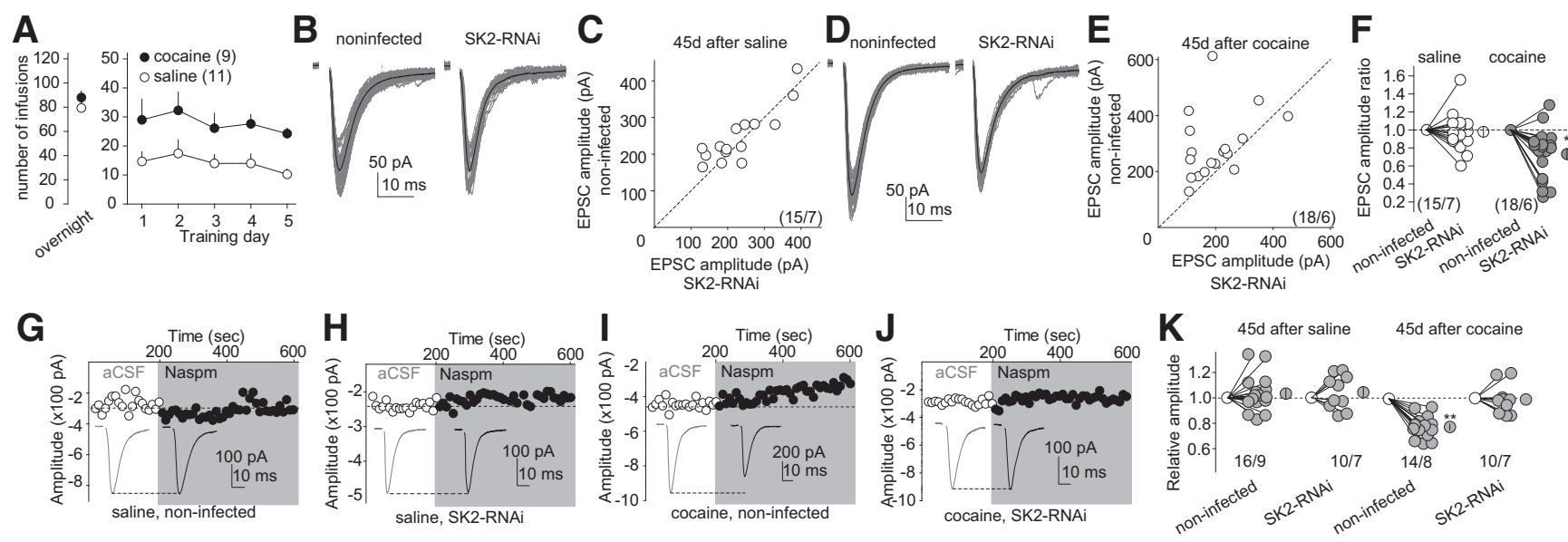

Figure 6. Preventing cocaine-induced upregulation of SK2 prevents CP AMPAR accumulation in NACSh MSNs after long-term withdrawal. $A$, Summary of self-administration training data for rats used in $\boldsymbol{B}-\boldsymbol{K} . \boldsymbol{B}$, Example traces simultaneously recorded from an SK2-RNAi-expressing and a noninfected neighboring MSN from a saline-exposed rat. C, Amplitudes of AMPAR EPSCs of MSNs expressing SK2-RNAi versus those of simultaneously recorded noninfected MSNs in saline-exposed rats. $\boldsymbol{D}$, Example traces simultaneously recorded from an SK2-RNAi-expressing and a noninfected neighboring MSN from a cocaine-exposed rat. $\boldsymbol{E}$, Amplitudes of AMPAR EPSCs of MSNs expressing SK2-RNAi versus those of simultaneously recorded noninfected MSNs in cocaine-exposed rats. $\boldsymbol{F}$, Summary showing that after $45 \mathrm{~d}$ of withdrawal from cocaine self-administration, EPSC amplitudes in SK2-RNAi-expressing NAcSh MSNs were significantly lower than those in noninfected MSNs. $\boldsymbol{G}-\boldsymbol{K}$, Example trials $(\boldsymbol{G}-\boldsymbol{J})$ and summary $(\boldsymbol{K})$ showing that after $45 \mathrm{~d}$ of withdrawal from cocaine self-administration, Naspm significantly inhibited AMPAR EPSCs in NAc MSNs, and this effect was prevented in MSNs expressing SK2-RNAi. ${ }^{*} p<0.05,{ }^{* *} p<0.01$.

important control experiments. First, $1 \mathrm{~d}$ after the selfadministration procedure (Fig. $5 B$ ), the amplitudes of EPSCs were similar between noninfected versus SK2-RNAi-expressing MSNs in saline-exposed rats $\left(t_{(13)}=0.61, p=0.55\right.$, cell-based paired $t$ test; Fig. $5 D-H)$. Because the basal level of SK2 in NAcSh MSNs was low (Fig. 4F-I), expression of SK2-RNAi did not affect the membrane excitability in control rats. These results also indicate that neither the AAV system nor expression of SK2-RNAi per se directly affects excitatory synapses. Second, $1 \mathrm{~d}$ after cocaine self-administration, the amplitudes of EPSCs were similar between noninfected versus SK2-RNAi-expressing NAcSh MSNs $\left(t_{(24)}=1.19, p=0.25\right.$, cell-based paired $t$ test; Fig. $\left.5 D-H\right)$. At this withdrawal time point, although the SK2-mediated membrane adaptation in NAcSh MSNs is accomplished (Fig. 4F-I), the excitatory synaptic strength has not been altered yet (Wolf, 2016). Thus, if the potential membrane-to-synapse SMHC is triggered after cocaine exposure, it is still in the initial stage without a detectable synaptic effect. As such, preventing the SK2-mediated membrane adaptation at this time-point does not affect excitatory synapses on NAcSh MSNs in cocaine-exposed rats. Consistent with these results, perfusion of the selective CP AMPAR antagonist Naspm did not significantly alter AMPAR EPSC amplitudes in either noninfected MSNs or SK2-expressing MSNs from saline- or cocaine-exposed rats on the first day of withdrawal $\left(F_{(1,52)}=0.63, p=0.43\right.$, cell-based two-way ANOVA; $F_{(1,27)}=0.38, p=0.54$, animal-based ANOVA; Fig. 5I-M). Therefore, viral-mediated expression of SK2-RNAi does not affect the subunit composition of synaptic AMPARs in early withdrawal.

Forty-five days after discontinuing cocaine self-administration, there is an overall strengthening of excitatory synapses in the NAc, primarily mediated by synaptic insertion of CP AMPARs (Wolf, 2016). To test whether this synaptic adaptation is achieved through SMHC triggered by the decreased membrane excitability, we expressed SK2-RNAi in the NAcSh 3 weeks before cocaine self-administration, and made pairwise recordings after $45 \mathrm{~d}$ of withdrawal. In saline-exposed control rats, no difference in EPSC amplitudes between SK2-RNAi-expressing MSNs and their neighboring noninfected MSNs was detected, indicating that ex- pression of SK2-RNAi does not change basal excitatory synaptic strength with this time course of viral expression $\left(t_{(14)}=0.36\right.$, $p=0.72$, cell-based paired $t$ test; Fig. $6 B, C)$. In cocaine-exposed rats, the EPSC amplitudes in SK2-RNAi-expressing NAcSh MSNs were significantly smaller compared with their neighboring noninfected MSNs $\left(t_{(17)}=4.03, p<0.01\right.$, cell-based paired $t$ test; Fig. $6 D-F)$. Given that strengthening of NAcSh excitatory synapses in noninfected MSNs has been accomplished at this withdrawal time-point, this result can be interpreted to indicate that the withdrawal-associated synaptic strengthening is prevented in SK2-RNAi-expressing MSNs. Consistently, application of Naspm significantly inhibited EPSCs in noninfected MSNs in cocaine-exposed rats, reflecting withdrawal-associated $\mathrm{CP}$ AMPAR accumulation, and this CP AMPAR accumulation was prevented in SK2-RNAi-expressing MSNs $\left(F_{(1,46)}=8.0, p<\right.$ 0.01 , cell-based two-way ANOVA; $p<0.01$ saline-noninfected vs cocaine-noninfected, $p<0.01$ cocaine-noninfected vs cocaineSK2-RNAi, $p>0.99$ saline-noninfected vs saline-SK2-RNAi, Bonferroni post-test; $F_{(1,27)}=8.2, p<0.01$, animal-based two-way ANOVA; $p<0.01$ cocaine-noninfected vs salinenoninfected, $p<0.01$ cocaine-noninfected vs cocaine-SK2RNAi, $p>0.99$ saline-noninfected vs saline-SK2-RNAi, Bonferroni post-test; Fig. $6 G-K)$. Thus, membrane-to-synapse SMHC-based dysregulation occurs over long-term withdrawal from cocaine self-administration, promoting synaptic accumulation of CP AMPARs in NAc MSNs.

\section{Preventing SMHC dysregulation prevents incubation of cocaine craving}

To test the role of SMHC in the incubation of cocaine craving, we bilaterally injected AAV2/8 expressing either GluN2B-RNAi or SK2-RNAi into the NAcSh of rats, thus preventing the SMHC cascade after cocaine through two different routes. Rats with intra-NAcSh injection of luciferase-RNAi-expressing AAV2/8 served as controls. Three weeks later, these rats were trained with the $5 \mathrm{~d}$ cocaine self-administration procedure, followed by either 1 or $45 \mathrm{~d}$ of withdrawal. Control rats assessed after $45 \mathrm{~d}$ of withdrawal exhibited higher levels of cue-induced cocaine seeking in a $1 \mathrm{~h}$ extinction test compared with rats assessed after only $1 \mathrm{~d}$ of 

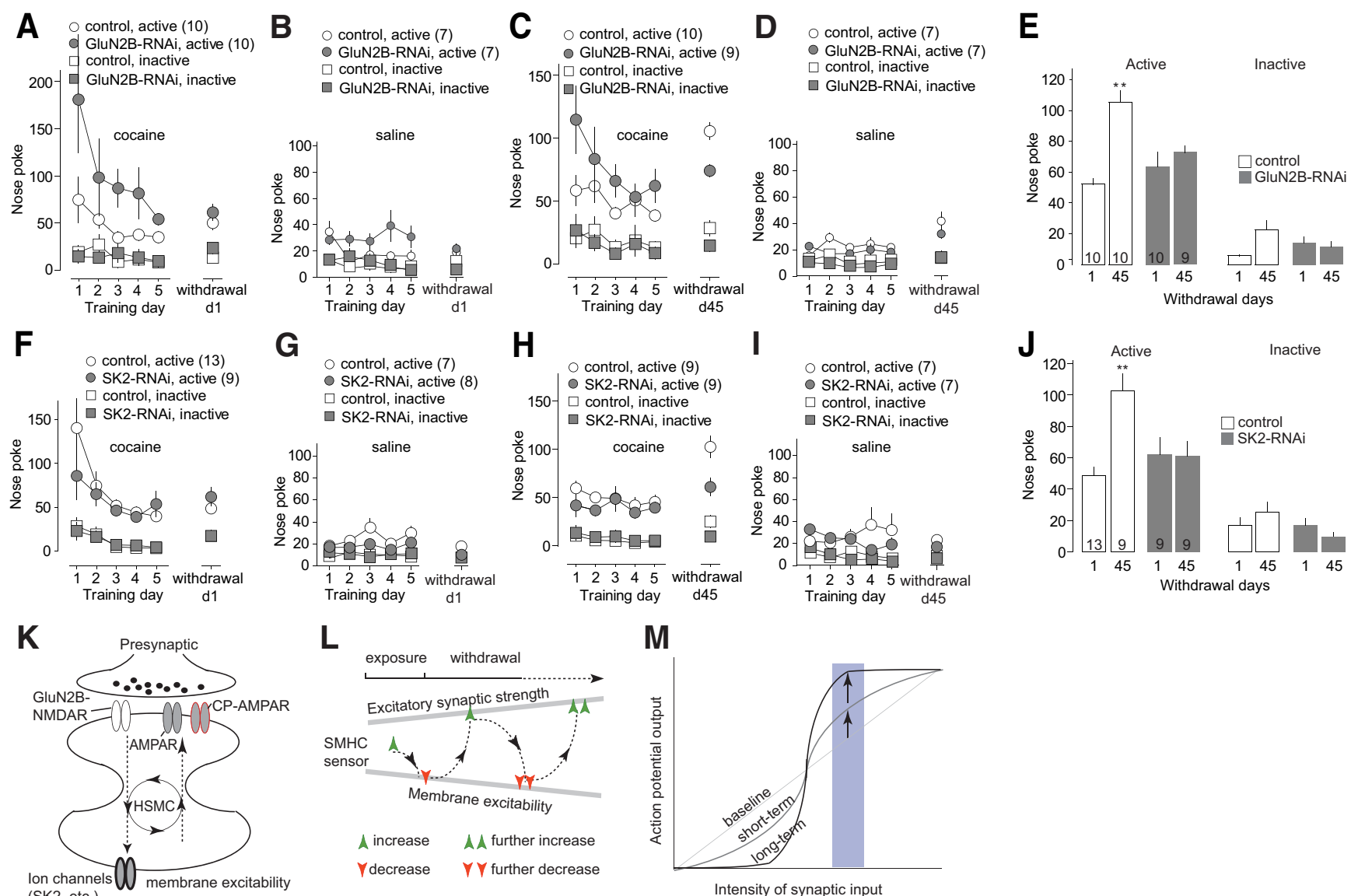

Ion channels
(SK2, etc.)

$\checkmark$ decrease

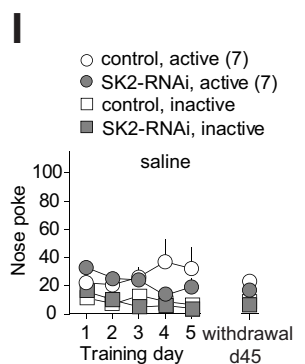

Figure 7. Preventing SMHC-mediated homeostatic dysregulation prevents incubation of cocaine craving. $\boldsymbol{A}, \boldsymbol{B}$, Summary showing nosepokes to active versus inactive holes of rats with intra-NACSh expression of GluN2B-RNAi or luciferase-RNAi (controls) during $5 \mathrm{~d}$ of cocaine $(\boldsymbol{A})$ or saline $(\boldsymbol{B})$ self-administration training $(2 \mathrm{~h} / \mathrm{d})$ and during the $1 \mathrm{~h}$ extinction test on withdrawal day 1. C, D, Summary showing nosepokes to active versus inactive holes of rats with intra-NACSh expression of GluN2B-RNAi or with intra-NAcSh expression of luciferase-RNAi (controls) during $5 \mathrm{~d}$ of cocaine $(\boldsymbol{C})$ or saline $(\boldsymbol{D})$ self-administration training $(2 \mathrm{~h} / \mathrm{d})$ and during the $1 \mathrm{~h}$ extinction test on withdrawal day 45 . $\boldsymbol{E}$, Summary showing that preventing cocaine-induced upregulation of GluN2B NMDARs prevented incubation of cocaine craving after drug withdrawal. $\boldsymbol{F}, \boldsymbol{G}$, Summary showing nosepokes to active versus inactive holes of rats with intra-NAcSh expression of SK2-RNAi or with intra-NAcSh expression of luciferase-RNAi (controls) during $5 \mathrm{~d}$ of cocaine $(\boldsymbol{F})$ or saline $(\boldsymbol{G})$ self-administration training $(2 \mathrm{~h} / \mathrm{d})$ and during the $1 \mathrm{~h}$ extinction test on withdrawal day 1 . $\boldsymbol{H}, \boldsymbol{I}$, Summary showing nosepokes to active versus inactive holes of rats with intra-NAcSh expression of SK2-RNAi or luciferase-RNAi (controls) during $5 \mathrm{~d}$ of cocaine $(\boldsymbol{H})$ or saline $(\boldsymbol{I})$ self-administration training $(2 \mathrm{~h} / \mathrm{d})$ and during the $1 \mathrm{~h}$ of extinction test on withdrawal day 45. J, Summary showing that preventing cocaine-induced upregulation of SK2 prevented incubation of cocaine craving after drug withdrawal. $\boldsymbol{K}$, Diagram showing two-way SMHC in NAcSh MSNs, in which the membrane excitability and excitatory synaptic strength are homeostatically coordinated. $\boldsymbol{L}$, Hypothetical diagram showing that, after cocaine self-administration, cascades of SMHC-mediated dysregulation lead to progressive increases in excitatory synaptic strength and decreases in membrane excitability in NAcSh MSNs. M, Diagram depicting the hypothesis that, after cocaine-induced SMHC dysregulation, NAcSh MSNs become preferentially responsive to relatively strong excitatory synaptic inputs but less responsive to weak inputs. ${ }^{* *} p<0.01$.

withdrawal, indicating incubation of cocaine craving (Fig. 7A-E). Intra-NAcSh knockdown of GluN2B prevented incubation of cocaine craving $\left(F_{(1,35)}=9.6, p<0.01\right.$, two-way ANOVA; $p<$ 0.01 luciferase-d 1 vs luciferase- $\mathrm{d} 45, p=0.02$ luciferase- $\mathrm{d} 45$ vs GluN2B-RNAi-d45, $p>0.99$ GluN2B-RNAi-d1 vs GluN2BRNAi-d45, Bonferroni post-test; Fig. 7A-E). Similarly, intra-NAc expression of SK2-RNAi also prevented the incubation of cocaine craving $\left(F_{(1,36)}=9.6, p<0.01\right.$, two-way ANOVA; $p<0.01$ luciferase-d1 vs luciferase-d45, $p=0.02$ luciferase-d45 vs SK2RNAi d45, $p>0.99$ SK2-RNAi-d1 vs SK2-RNAi-d45, Bonferroni post-test; Fig. $7 F-J$ ). Thus, cocaine-induced SMHC cascades in NAcSh MSNs promote incubation of cocaine craving.

\section{Discussion}

Our current results demonstrate a bidirectional SMHC (Fig. 7K), through which two critical physiological parameters interact to coordinate the functional output of NAcSh MSNs. Furthermore, upregulation of GluN2B NMDARs after cocaine selfadministration initiates cascades of SMHC to sequentially change the membrane excitability and AMPAR-mediated excitatory strength of NAcSh MSNs (Fig. 7L).

\section{GluN2B NMDAR signaling}

Our previous results showed that upregulation or downregulation of AMPAR-mediated excitatory synaptic strength induces homeostatic downregulation or upregulation of membrane excitability in NAcSh MSNs (Ishikawa et al., 2009). Our present results identify the GluN2B NMDAR subtype as the sensor of excitatory synaptic strength that subsequently engages SMHC.

In vivo, striatal MSNs often reside at upstate membrane potentials ( - $55 \mathrm{mV}$; Mahon et al., 2006), where the $\mathrm{Mg}^{2+}$ mediated blockade of NMDARs is partially relieved (Jahr and Stevens, 1990). The $\mathrm{Mg}^{2+}$ blockade curve rises/declines sharply around upstate membrane potentials (Jahr and Stevens, 1990), such that small changes of the membrane potential by altered excitatory inputs may be translated into substantial changes in basal NMDAR activity, rendering NMDARs highly sensitive in monitoring excitatory synaptic strength. 
NMDARs in the adult forebrain are thought to exist as tetramers primarily consisting of GluN1 and GluN2 subunits (Monyer et al., 1994; Standaert et al., 1994). In NAcSh MSNs, 25\% of synaptic NMDARs contain GluN2B (Huang et al., 2011; Graziane et al., 2016). Compared with GluN2A NMDARs, GluN2B NMDARs exhibit slower decay kinetics, and thus can remain active during trains of synchronous synaptic activation, which is typical for in vivo NAcSh MSNs (Vicini et al., 1998; O'Donnell et al., 1999). Furthermore, GluN2B NMDARs exhibit a high ability to augment and prolong postsynaptic CaMKII signaling (Strack and Colbran, 1998; Leonard et al., 1999; Strack et al., 2000; Mayadevi et al., 2002; Halt et al., 2012). These properties endow GluN2B NMDARs with a unique role in synaptic plasticity (Tang et al., 1999, 2001; Wong et al., 2002; Liu et al., 2004; Massey et al., 2004; Barria and Malinow, 2005; Berberich et al., 2005; Halt et al., 2012). Our current results suggest that, with these properties, upregulated GluN2B NMDARs engage SMHC for cascades of cellular adaptations in NAcSh MSNs after drug withdrawal. It is worth noting that our results cannot rule out the possibility that the increased GluN2B-signaling may also operates independently of MSHC to regulate synaptic and membrane substrates.

Although synaptic transmission is likely the main source of glutamate that activates GluN2B-signaling, glial source should not be ignored. Glial cells are critically important for brain glutamate homeostasis. After cocaine self-administration, certain glial-mediated glutamate reuptake mechanisms are compromised, resulting in elevated levels of extracellular glutamate (Scofield and Kalivas, 2014). This ambient glutamate may operate together with synaptically released glutamate to augment excitatory tone and promote SMHC.

Synaptic expression of GluN2B NMDARs is sensitively regulated by development. In our experiments, animals ranging in age from $6 \mathrm{~d}$ (slice cultures) to 20 weeks (after $45 \mathrm{~d}$ withdrawal) were used. Although results from these animals consistently suggest the critical role of GluN2B NMDARs in SMHC, we cannot rule out the possibility that developmental regulation of GluN2B NMDARs influences the magnitude or pattern of SMHC. It is also important to note that NAc MSNs are highly heterogeneous. For example, they can be divided into dopamine receptor D1versus D2-expressing neurons that can play distinct functional roles (Smith et al., 2013). Future studies should conduct parallel examinations of membrane excitability and synaptic strength in each population following cocaine self-administration.

\section{SMHC in early withdrawal from cocaine}

We showed previously that elevation of GluN2B expression in NAcSh MSNs during noncontingent cocaine injections corresponded to the generation of GluN2B-enriched silent synapses (Huang et al., 2009; Brown et al., 2011). After similar noncontingent procedures, the AMPAR/NMDAR ratio at NAcSh synapses is decreased after $1 \mathrm{~d}$ of withdrawal from cocaine (Kourrich and Thomas, 2009), whereas surface AMPARs are unchanged (Boudreau and Wolf, 2005). Thus, upregulation of GluN2B NMDARs may underlie the decreased AMPAR/NMDAR ratio.

During the first round of SMHC, we show that one of the targeted membrane substrates is the SK2 channel, and that preventing cocaine-induced upregulation of synaptic GluN2B NMDARs prevents SK2 upregulation (Figs. 3, 4F, G). Importantly, SK2 is likely not the only membrane substrate responding to synaptic signals. It is conceivable that, in most homeostatic responses including SMHC, cells will mobilize a wide range of adaptations to maintain overall functional stabilization. Consistent with this scenario, it has also been observed that voltage- gated potassium currents are increased, whereas voltage-gated sodium and calcium currents are decreased in NAcSh MSNs after cocaine exposure, all likely contributing to decreased membrane excitability (Zhang et al., 1998, 2002; Hu et al., 2004; Dong et al., 2006; Kourrich et al., 2013).

\section{SMHC in late withdrawal from cocaine}

After prolonged withdrawal from cocaine self-administration, CP AMPARs accumulate in both NAc shell and core (Conrad et al., 2008; Lee et al., 2013; Ma et al., 2014). Thereafter, manipulations that remove or block CP AMPARs in either region inhibit expression of incubated craving (Conrad et al., 2008; Lee et al., 2013; Loweth et al., 2014; Ma et al., 2014). The requirement for activation of both core and shell may be explained by interconnections between these regions (Haber et al., 2000; Ikemoto, 2007).

The present findings identify one mechanism contributing to CP AMPAR accumulation, namely a second round of SMHC. We demonstrated this by developing an RNAi approach to prevent cocaine-induced upregulation of SK2, and showing that this manipulation prevented synaptic accumulation of CP AMPARs assessed after $45 \mathrm{~d}$ withdrawal from cocaine (Fig. 6). Although these results indicate that upregulation of SK2 is essential for withdrawal-associated CP AMPAR accumulation, other mechanisms may also be required, as reviewed recently (Dong et al., 2017), and discussed below.

\section{Early and late SMHC: relationship}

Mechanisms leading to upregulation of AMPARs in classical synaptic scaling have been extensively studied in cortical and hippocampal neurons (Turrigiano and Nelson, 2004; Yee et al., 2017) and one study has characterized mechanisms in cultured NAc MSNs (Sun and Wolf, 2009). In contrast, the mechanisms that mediate CP AMPAR accumulation during membrane-tosynapse SMHC during cocaine withdrawal are less clear, and may differ between NAc core and shell.

After cocaine self-administration, an increase in GluN2B NMDARs in NAcSh MSNs was observed after $1 \mathrm{~d}$ of withdrawal (Fig. 2), corresponding to an increase in silent synapses, which matured partially by recruiting CP AMPARs as withdrawal proceeded (Lee et al., 2013; Ma et al., 2014). In late withdrawal, optogenetic LTD to remove CP AMPARs restored high levels of silent synapses (Lee et al., 2013; Ma et al., 2014). The timing of these events is largely consistent with the idea that silent synapses gradually mature through the addition of CP AMPARs, which subsequently contribute to incubated cocaine craving. In theory, this maturation could resemble a developmental process in hippocampus whereby silent synapses, through a Hebbian process, preferentially recruit CP AMPARs (Shi et al., 2001). However, there are no obvious Hebbian stimuli during drug withdrawal for animals in their home-cages. Thus, SMHC may provide a major driving force for synaptic accumulation of CP AMPARs. Furthermore, as withdrawal proceeds, we cannot rule out the possibility that CP AMPARs also move into non-silent synapses.

In NAc core, an extended-access cocaine self-administration regimen $(6 \mathrm{~h} / \mathrm{d} \times 10 \mathrm{~d})$ leads to $\mathrm{CP}$ AMPAR accumulation only after $\sim 30 \mathrm{~d}$ of withdrawal (Wolf and Tseng, 2012). Preliminary results suggest that NMDAR plasticity also occurs in NAc core MSNs during incubation (Christian et al., 2017). In addition, a withdrawal-dependent reduction in mGluR1 expression, leading to impaired mGluR1-mediated removal of synaptic CP AMPARs, precedes and enables the synaptic accumulation of CP AMPARs (Loweth et al., 2014). It will be 
important to determine the extent to which this mechanism contributes in NAcSh MSNs and, conversely, the extent to which SMHC contributes in NAc core.

\section{Significance of homeostatic dysregulation cascades}

In NAcSh MSNs, excitatory synaptic input serves as the main driving force for action potential firing, an output gated by the membrane excitability. SMHC functions to maintain stability of this input-output relationship. Our present results depict two elements in a cascade of SMHC-based dysregulation over the $45 \mathrm{~d}$ cocaine withdrawal period, and it is possible that this homeostatic dysregulation continues cascading thereafter (Fig. $7 L$ ). If a single NAcSh MSN is conceptualized as a linear electrical system with an input, a gain, and an output, cocaine-induced SMHC cascades may progressively increase the input and reduce the gain simultaneously, which keeps the input-output balanced at the check point (Fig. $7 M$, middle point hypothesized as the check point), but increases the output variability anywhere else, polarizing the input-output relationship. Specifically, after long-term withdrawal from cocaine, low-intensity excitatory synaptic inputs, which otherwise would trigger action potential firing in drug-naive rats, may fail to do so due to the substantially reduced membrane excitability. On the other hand, high-intensity inputs can pass the hurdle of the reduced membrane excitability, and possibly predominate in triggering action potential firing. As such, normal, low-intensity inputs to NAcSh MSNs may be suppressed after withdrawal from cocaine, whereas highintensity inputs, some of which may convey cocaine-related information, are prioritized for functional output. This may bias NAc output toward cocaine-related behaviors.

\section{References}

Aghajanian GK (1978) Tolerance of locus coeruleus neurons to morphine and suppression of withdrawal response by clonidine. Nature 276:186188. CrossRef Medline

Barria A, Malinow R (2005) NMDA receptor subunit composition controls synaptic plasticity by regulating binding to CaMKII. Neuron 48:289-301. CrossRef Medline

Berberich S, Punnakkal P, Jensen V, Pawlak V, Seeburg PH, Hvalby Ø, Köhr G (2005) Lack of NMDA receptor subtype selectivity for hippocampal long-term potentiation. J Neurosci 25:6907-6910. CrossRef Medline

Boudreau AC, Wolf ME (2005) Behavioral sensitization to cocaine is associated with increased AMPA receptor surface expression in the nucleus accumbens. J Neurosci 25:9144-9151. CrossRef Medline

Brown TE, Lee BR, Mu P, Ferguson D, Dietz D, Ohnishi YN, Lin Y, Suska A, Ishikawa M, Huang YH, Shen H, Kalivas PW, Sorg BA, Zukin RS, Nestler EJ, Dong Y, Schlüter OM (2011) A silent synapse-based mechanism for cocaine-induced locomotor sensitization. J Neurosci 31:8163-8174. CrossRef Medline

Christian D, Tseng KY, Wolf M (2017) Extended access cocaine selfadministration leads to increased GluN3-containing NMDA receptor function in the rat nucleus accumbens. Soc Neurosci Abstr 43:334.15.

Conrad KL, Tseng KY, Uejima JL, Reimers JM, Heng LJ, Shaham Y, Marinelli M, Wolf ME (2008) Formation of accumbens GluR2-lacking AMPA receptors mediates incubation of cocaine craving. Nature 454:118-121. CrossRef Medline

Cull-Candy SG, Leszkiewicz DN (2004) Role of distinct NMDA receptor subtypes at central synapses. Sci STKE 2004:re16. CrossRef Medline

Dong Y, Green T, Saal D, Marie H, Neve R, Nestler EJ, Malenka RC (2006) CREB modulates excitability of nucleus accumbens neurons. Nat Neurosci 9:475-477. CrossRef Medline

Dong Y, Nasif FJ, Tsui JJ, Ju WY, Cooper DC, Hu XT, Malenka RC, White FJ (2005) Cocaine-induced plasticity of intrinsic membrane properties in prefrontal cortex pyramidal neurons: adaptations in potassium currents. J Neurosci 25:936-940. CrossRef Medline

Dong Y, Taylor JR, Wolf ME, Shaham Y (2017) Circuit and synaptic plasticity mechanisms of drug relapse. J Neurosci 37:10867-10876. CrossRef Medline
Graziane NM, Sun S, Wright WJ, Jang D, Liu Z, Huang YH, Nestler EJ, Wang YT, Schlüter OM, Dong Y (2016) Opposing mechanisms mediate morphine- and cocaine-induced generation of silent synapses. Nat Neurosci 19:915-925. CrossRef Medline

Grimm JW, Hope BT, Wise RA, Shaham Y (2001) Neuroadaptation: incubation of cocaine craving after withdrawal. Nature 412:141-142. CrossRef Medline

Haber SN, Fudge JL, McFarland NR (2000) Striatonigrostriatal pathways in primates form an ascending spiral from the shell to the dorsolateral striatum. J Neurosci 20:2369-2382. Medline

Halt AR, Dallapiazza RF, Zhou Y, Stein IS, Qian H, Juntti S, Wojcik S, Brose N, Silva AJ, Hell JW (2012) CaMKII binding to GluN2B is critical during memory consolidation. EMBO J 31:1203-1216. CrossRef Medline

Huang YH, Lin Y, Brown TE, Han MH, Saal DB, Neve RL, Zukin RS, Sorg BA, Nestler EJ, Malenka RC, Dong Y (2008) CREB modulates the functional output of nucleus accumbens neurons: a critical role of $N$-methyl-Daspartate glutamate receptor (NMDAR) receptors. J Biol Chem 283: 2751-2760. CrossRef Medline

Huang YH, Lin Y, Mu P, Lee BR, Brown TE, Wayman G, Marie H, Liu W, Yan Z, Sorg BA, Schlüter OM, Zukin RS, Dong Y (2009) In vivo cocaine experience generates silent synapses. Neuron 63:40-47. CrossRef Medline

Huang YH, Schlüter OM, Dong Y (2011) Cocaine-induced homeostatic regulation and dysregulation of nucleus accumbens neurons. Behav Brain Res 216:9-18. CrossRef Medline

Huang X, Stodieck SK, Goetze B, Cui L, Wong MH, Wenzel C, Hosang L, Dong Y, Löwel S, Schluter OM (2015) Progressive maturation of silent synapses governs the duration of a critical period. Proc Natl Acad Sci U S A 112:E3131-E3140. CrossRef Medline

Hu XT, Basu S, White FJ (2004) Repeated cocaine administration suppresses HVA-Ca ${ }^{2+}$ potentials and enhances activity of $\mathrm{K}+$ channels in rat nucleus accumbens neurons. J Neurophysiol 92:1597-1607. CrossRef Medline

Hyman SE, Malenka RC, Nestler EJ (2006) Neural mechanisms of addiction: the role of reward-related learning and memory. Annu Rev Neurosci 29:565-598. CrossRef Medline

Ikemoto S (2007) Dopamine reward circuitry: two projection systems from the ventral midbrain to the nucleus accumbens-olfactory tubercle complex. Brain Res Rev 56:27-78. CrossRef Medline

Ishikawa M, Mu P, Moyer JT, Wolf JA, Quock RM, Davies NM, Hu XT, Schlüter OM, Dong Y (2009) Homeostatic synapse-driven membrane plasticity in nucleus accumbens neurons. J Neurosci 29:5820-5831. CrossRef Medline

Jahr CE, Stevens CF (1990) Voltage dependence of NMDA-activated macroscopic conductances predicted by single-channel kinetics. J Neurosci 10:3178-3182. CrossRef Medline

Kalivas PW (2005) How do we determine which drug-induced neuroplastic changes are important? Nat Neurosci 8:1440-1441. CrossRef Medline

Koob GF, Le Moal M (1997) Drug abuse: hedonic homeostatic dysregulation. Science 278:52-58. CrossRef Medline

Kourrich S, Hayashi T, Chuang JY, Tsai SY, Su TP, Bonci A (2013) Dynamic interaction between sigma-1 receptor and Kv1.2 shapes neuronal and behavioral responses to cocaine. Cell 152:236-247. CrossRef Medline

Kourrich S, Rothwell PE, Klug JR, Thomas MJ (2007) Cocaine experience controls bidirectional synaptic plasticity in the nucleus accumbens. J Neurosci 27:7921-7928. CrossRef Medline

Kourrich S, Thomas MJ (2009) Similar neurons, opposite adaptations: psychostimulant experience differentially alters firing properties in accumbens core versus shell. J Neurosci 29:12275-12283. CrossRef Medline

Lee BR, Ma YY, Huang YH, Wang X, Otaka M, Ishikawa M, Neumann PA, Graziane NM, Brown TE, Suska A, Guo C, Lobo MK, Sesack SR, Wolf ME, Nestler EJ, Shaham Y, Schlüter OM, Dong Y (2013) Maturation of silent synapses in amygdala-accumbens projection contributes to incubation of cocaine craving. Nat Neurosci 16:1644-1651. CrossRef Medline

Leonard AS, Lim IA, Hemsworth DE, Horne MC, Hell JW (1999) Calcium/ calmodulin-dependent protein kinase II is associated with the $\mathrm{N}$-methylD-aspartate receptor. Proc Natl Acad Sci U S A 96:3239-3244. CrossRef Medline

Liu L, Wong TP, Pozza MF, Lingenhoehl K, Wang Y, Sheng M, Auberson YP, Wang YT (2004) Role of NMDA receptor subtypes in governing the direction of hippocampal synaptic plasticity. Science 304:1021-1024. CrossRef Medline 
Loweth JA, Scheyer AF, Milovanovic M, LaCrosse AL, Flores-Barrera E, Werner CT, Li X, Ford KA, Le T, Olive MF, Szumlinski KK, Tseng KY, Wolf ME (2014) Synaptic depression via mGluR1 positive allosteric modulation suppresses cue-induced cocaine craving. Nat Neurosci 17:73-80. CrossRef Medline

Lu L, Grimm JW, Hope BT, Shaham Y (2004) Incubation of cocaine craving after withdrawal: a review of preclinical data. Neuropharmacology 47: 214-226. CrossRef Medline

Ma YY, Lee BR, Wang X, Guo C, Liu L, Cui R, Lan Y, Balcita-Pedicino JJ, Wolf ME, Sesack SR, Shaham Y, Schlüter OM, Huang YH, Dong Y (2014) Bidirectional modulation of incubation of cocaine craving by silent synapse-based remodeling of prefrontal cortex to accumbens projections. Neuron 83:1453-1467. CrossRef Medline

Mahon S, Vautrelle N, Pezard L, Slaght SJ, Deniau JM, Chouvet G, Charpier S (2006) Distinct patterns of striatal medium spiny neuron activity during the natural sleep-wake cycle. J Neurosci 26:12587-12595. CrossRef Medline

Marie H, Morishita W, Yu X, Calakos N, Malenka RC (2005) Generation of silent synapses by acute in vivo expression of CaMKIV and CREB. Neuron 45:741-752. CrossRef Medline

Massey PV, Johnson BE, Moult PR, Auberson YP, Brown MW, Molnar E, Collingridge GL, Bashir ZI (2004) Differential roles of NR2A and NR2B-containing NMDA receptors in cortical long-term potentiation and long-term depression. J Neurosci 24:7821-7828. CrossRef Medline

Mayadevi M, Praseeda M, Kumar KS, Omkumar RV (2002) Sequence determinants on the NR2A and NR2B subunits of NMDA receptor responsible for specificity of phosphorylation by CaMKII. Biochim Biophys Acta 1598:40-45. CrossRef Medline

Monyer H, Burnashev N, Laurie DJ, Sakmann B, Seeburg PH (1994) Developmental and regional expression in the rat brain and functional properties of four NMDA receptors. Neuron 12:529-540. CrossRef Medline

Mu P, Moyer JT, Ishikawa M, Zhang Y, Panksepp J, Sorg BA, Schlüter OM, Dong Y (2010) Exposure to cocaine dynamically regulates the intrinsic membrane excitability of nucleus accumbens neurons. J Neurosci 30: 3689-3699. CrossRef Medline

Nestler EJ (2001) Molecular basis of long-term plasticity underlying addiction. Nat Rev Neurosci 2:119-128. CrossRef Medline

Nestler EJ, Aghajanian GK (1997) Molecular and cellular basis of addiction. Science 278:58-63. CrossRef Medline

O’Donnell P, Greene J, Pabello N, Lewis BL, Grace AA (1999) Modulation of cell firing in the nucleus accumbens. Ann N Y Acad Sci 877:157-175. CrossRef Medline

Parvaz MA, Moeller SJ, Goldstein RZ (2016) Incubation of cue-induced craving in adults addicted to cocaine measured by electroencephalography. JAMA Psychiatry 73:1127-1134. CrossRef Medline

Scofield MD, Kalivas PW (2014) Astrocytic dysfunction and addiction: consequences of impaired glutamate homeostasis. Neuroscientist 20:610622. CrossRef Medline

Shi S, Hayashi Y, Esteban JA, Malinow R (2001) Subunit-specific rules governing AMPA receptor trafficking to synapses in hippocampal pyramidal neurons. Cell 105:331-343. CrossRef Medline
Smith RJ, Lobo MK, Spencer S, Kalivas PW (2013) Cocaine-induced adaptations in D1 and D2 accumbens projection neurons (a dichotomy not necessarily synonymous with direct and indirect pathways). Curr Opin Neurobiol 23:546-552. CrossRef Medline

Standaert DG, Testa CM, Young AB, Penney JB Jr (1994) Organization of $\mathrm{N}$-methyl-D-aspartate glutamate receptor gene expression in the basal ganglia of the rat. J Comp Neurol 343:1-16. CrossRef Medline

Strack S, Colbran RJ (1998) Autophosphorylation-dependent targeting of calcium/calmodulin-dependent protein kinase II by the NR2B subunit of the $N$-methyl-D-aspartate receptor. J Biol Chem 273:20689-20692. CrossRef Medline

Strack S, McNeill RB, Colbran RJ (2000) Mechanism and regulation of calcium/calmodulin-dependent protein kinase II targeting to the NR2B subunit of the N-methyl-D-aspartate receptor. J Biol Chem 275:23798 23806. CrossRef Medline

Sun X, Wolf ME (2009) Nucleus accumbens neurons exhibit synaptic scaling that is occluded by repeated dopamine pre-exposure. Eur J Neurosci 30:539-550. CrossRef Medline

Tang YP, Shimizu E, Dube GR, Rampon C, Kerchner GA, Zhuo M, Liu G, Tsien JZ (1999) Genetic enhancement of learning and memory in mice. Nature 401:63-69. CrossRef Medline

Tang YP, Wang H, Feng R, Kyin M, Tsien JZ (2001) Differential effects of enrichment on learning and memory function in NR2B transgenic mice. Neuropharmacology 41:779-790. CrossRef Medline

Turrigiano GG, Nelson SB (2004) Homeostatic plasticity in the developing nervous system. Nat Rev Neurosci 5:97-107. CrossRef Medline

Vicini S, Wang JF, Li JH, Zhu WJ, Wang YH, Luo JH, Wolfe BB, Grayson DR (1998) Functional and pharmacological differences between recombinant $N$-methyl-D-aspartate receptors. J Neurophysiol 79:555-566. CrossRef Medline

White NM (1996) Addictive drugs as reinforcers: multiple partial actions on memory systems. Addiction 91:921-949; discussion 951-965. CrossRef Medline

Wolf ME (2016) Synaptic mechanisms underlying persistent cocaine craving. Nat Rev Neurosci 17:351-365. CrossRef Medline

Wolf ME, Tseng KY (2012) Calcium-permeable AMPA receptors in the VTA and nucleus accumbens after cocaine exposure: when, how, and why? Front Mol Neurosci 5:72. CrossRef Medline

Wong RW, Setou M, Teng J, Takei Y, Hirokawa N (2002) Overexpression of motor protein KIF17 enhances spatial and working memory in transgenic mice. Proc Natl Acad Sci U S A 99:14500-14505. CrossRef Medline

Yee AX, Hsu YT, Chen L (2017) A metaplasticity view of the interaction between homeostatic and Hebbian plasticity. Philos Trans R Soc Lond B Biol Sci 372:20160155. CrossRef Medline

Zhang XF, Hu XT, White FJ (1998) Whole-cell plasticity in cocaine withdrawal: reduced sodium currents in nucleus accumbens neurons. J Neurosci 18:488-498. CrossRef Medline

Zhang XF, Cooper DC, White FJ (2002) Repeated cocaine treatment decreases whole-cell calcium current in rat nucleus accumbens neurons. J Pharmacol Exp Ther 301:1119-1125. CrossRef Medline 